\title{
The Relationship between the Distributed Leadership Readiness of West Virginia Principals and Their Perceptions of Selected School-based Committees
}

\author{
Patrick L. Riddle II
}

Follow this and additional works at: https://researchrepository.wvu.edu/etd

\section{Recommended Citation}

Riddle II, Patrick L., "The Relationship between the Distributed Leadership Readiness of West Virginia Principals and Their Perceptions of Selected School-based Committees" (2015). Graduate Theses, Dissertations, and Problem Reports. 6504.

https://researchrepository.wvu.edu/etd/6504

This Dissertation is protected by copyright and/or related rights. It has been brought to you by the The Research Repository @ WVU with permission from the rights-holder(s). You are free to use this Dissertation in any way that is permitted by the copyright and related rights legislation that applies to your use. For other uses you must obtain permission from the rights-holder(s) directly, unless additional rights are indicated by a Creative Commons license in the record and/ or on the work itself. This Dissertation has been accepted for inclusion in WVU Graduate Theses, Dissertations, and Problem Reports collection by an authorized administrator of The Research Repository @ WVU.

For more information, please contact researchrepository@mail.wvu.edu. 
The Relationship between the Distributed Leadership Readiness of West Virginia Principals and Their Perceptions of Selected School-based Committees

Patrick L. Riddle II

West Virginia University

Dissertation submitted to

The College of Education and Human Services at

West Virginia University

In partial fulfillment of the requirements for the degree of

\author{
Doctor of Education \\ In \\ Educational Leadership Studies
}

Helen M. Hazi, Ph.D., Chair

Charline Barnes-Rowland, Ed.D.

Kathy Finsley, J.D.

M Cecil Smith, Ph.D.

Neal Shambaugh, Ph.D.

Morgantown, West Virginia

2015

Keywords: Leadership, Distributed, Education, School-Based Copyright 2015 Patrick Riddle 


\begin{abstract}
The Relationship between the Distributed Leadership Readiness of West Virginia Principals and Their Perceptions of Selected School-based Committees

\section{Patrick Riddle}

The purpose of this study was to determine the relationship between the distributed leadership readiness of West Virginia principals and their perceptions of selected school-based committees which influence leadership in their schools. Six hundred seventy four West Virginia principals were invited to participate in this study by responding to an online survey that included the Distributed Leadership Readiness Scale (DLRS), demographic items, and items from the researcher developed School-Based Committee Influence Survey. There were 198 West Virginia principal respondents to the survey (29.3\%). The results of this study showed that West Virginia principal respondents were ready for distributed leadership and saw a relationship with the selected school-based committees. The school leadership team, school curriculum team, and faculty senate were perceived to have the most influence on the leadership of the school. The results showed the school curriculum team with a strong relationship with the perceived level of distributed leadership readiness. Lastly, the results showed that differences existed between some of the demographic factors and perceived level of distributed leadership readiness with some of the DLRS dimensions. Gender had significant differences within the dimensions of School Culture and Shared Responsibility; years of experience in their school had significant differences within the dimensions of Mission, Vision, and Goals and Shared Responsibility; and programmatic level had significant differences with the dimension of Shared Responsibility. 


\section{Acknowledgements}

My dissertation journey was longer than expected and would not have been possible without the support of my wonderful wife and children. They were always in my corner and never faltered in their support for me. I knew that I could count on them to provide me the love, prayers, and support I needed to finish my journey. They made sacrifices to get me to the end of this journey. I will be forever thankful to them for those sacrifices. I am proud to have completed my journey and for my children to see me finish this race.

This journey would not have ended successfully without the expertise and support of Dr. Helen Hazi. She was able to provide me with the organization I needed to write my dissertation, but also knew how to motivate me before my timeline expired. Without her dedication and advocacy, I would forever been stuck at ABD (All But Dissertation). She was a blessing to me

during this process. I also could not have made it through without the statistical help of Larry White. He was there to guide me, answer questions, and help me to understand each aspect I needed to complete my study.

Lastly, I am grateful to friends, family, and colleagues who provided support and encouragement during my work. Many of these individuals not only encouraged me, but worked with me during the writing process. Their patience and belief in me drove me forward throughout my journey. 


\section{Contents}

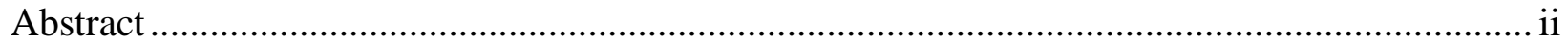

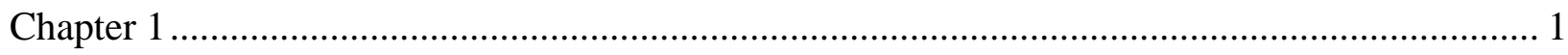

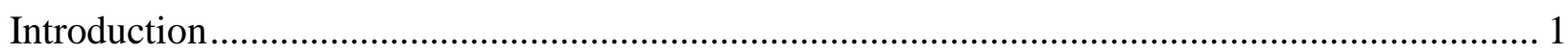

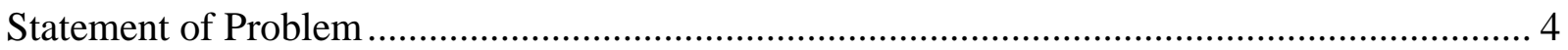

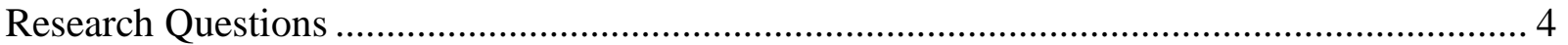

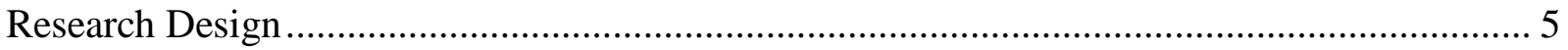

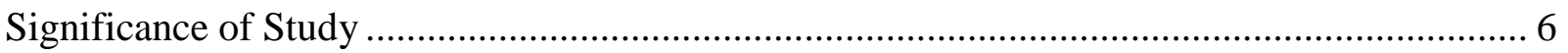

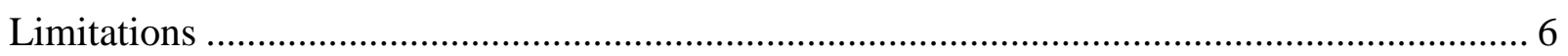

Definitions of Terms .................................................................................................... 7

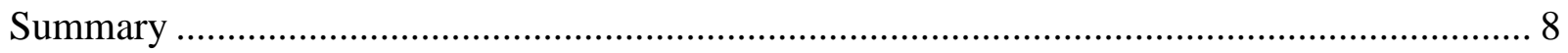

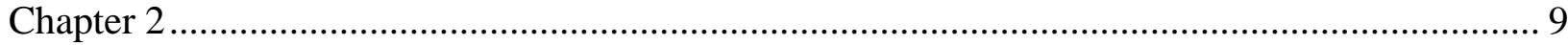

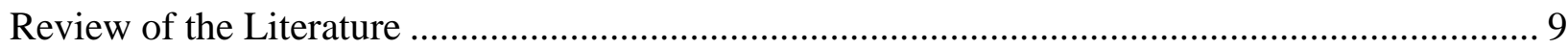

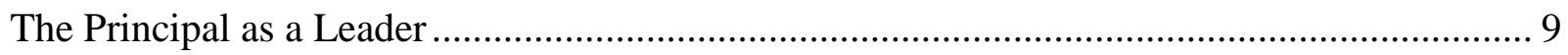

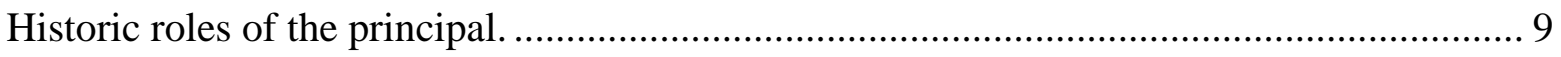

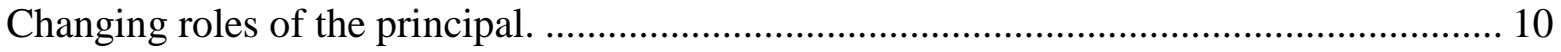

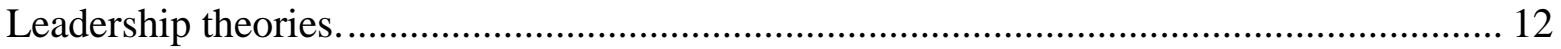

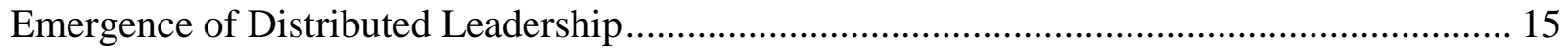

Current Distributed Leadership Research ................................................................. 18

Instruments for Distributed Leadership..................................................................... 20

Distributed Leadership Readiness Scale ....................................................................... 24

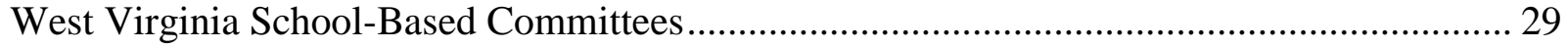

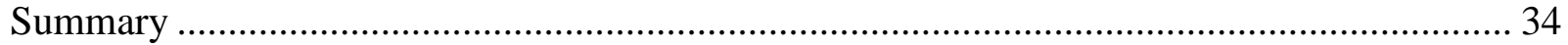

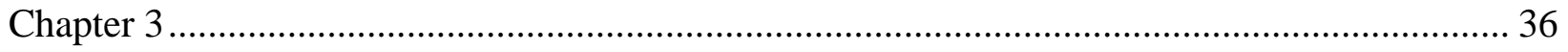

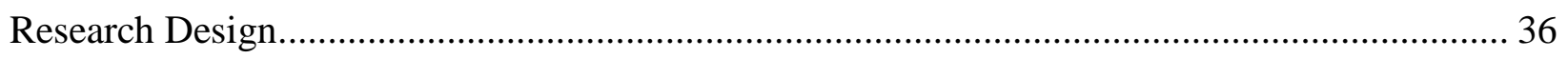

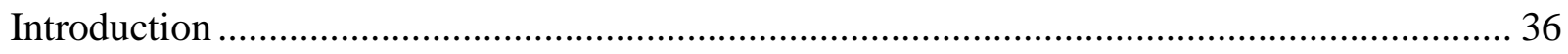

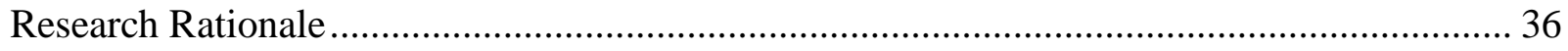

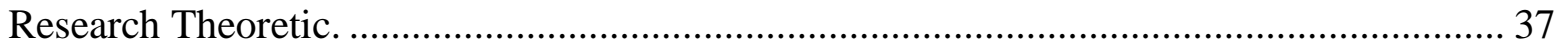

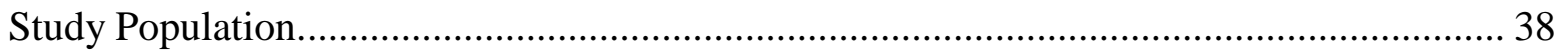

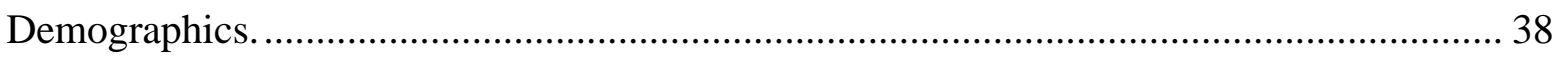

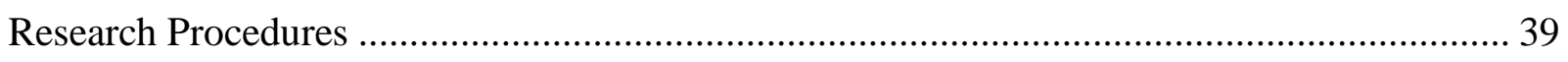

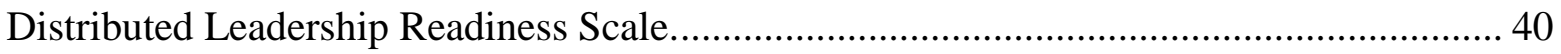




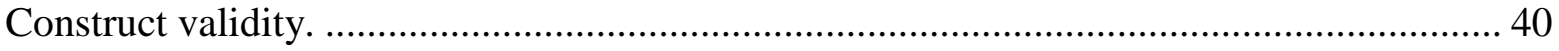

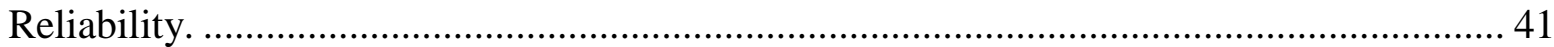

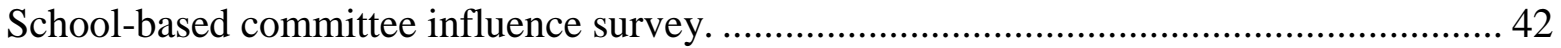

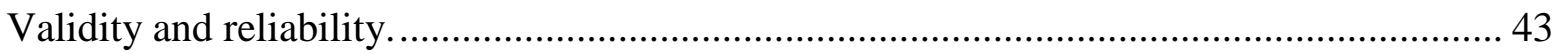

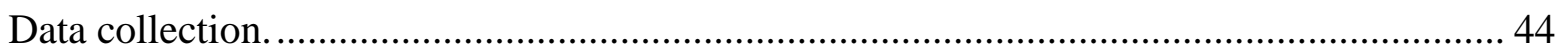

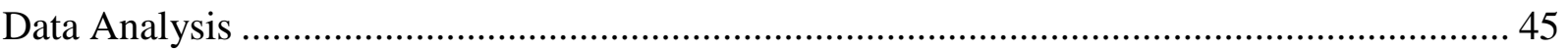

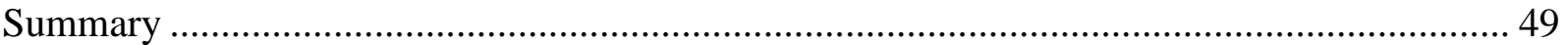

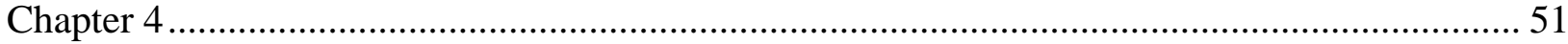

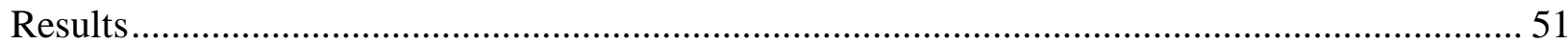

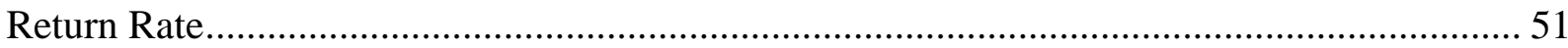

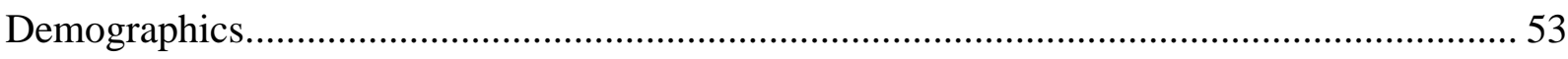

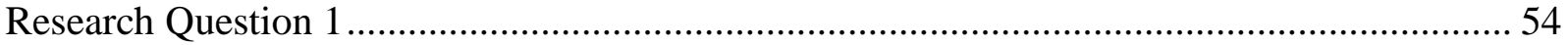

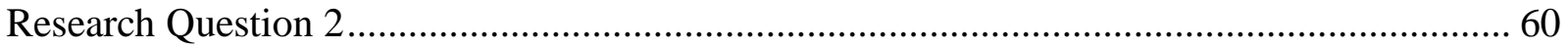

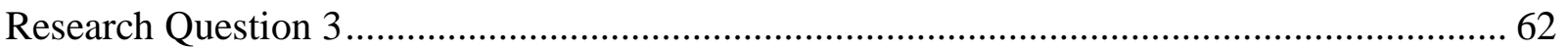

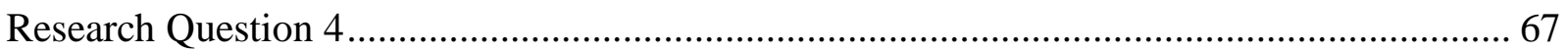

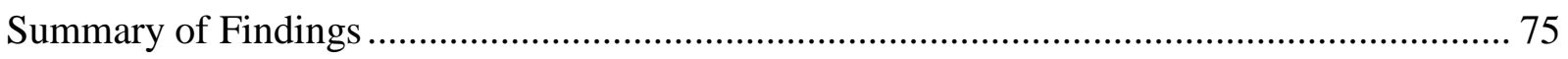

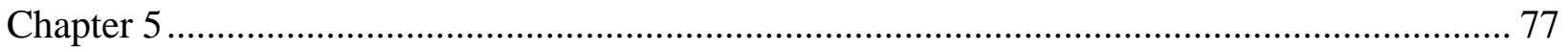

Summary, Conclusions, Discussion, and Recommendations ……………………….................. 77

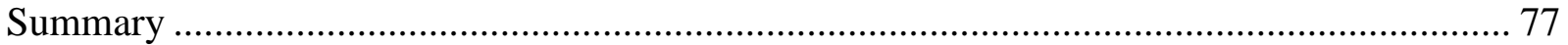

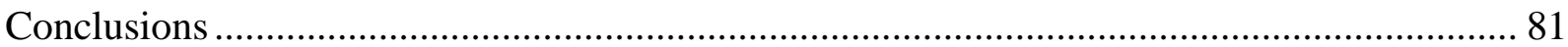

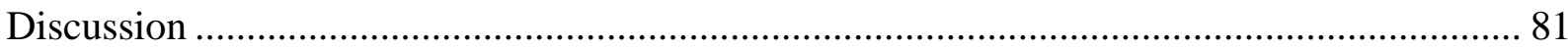

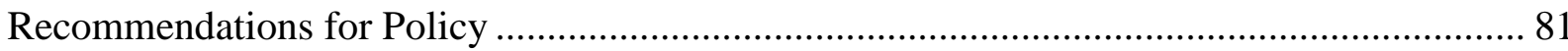

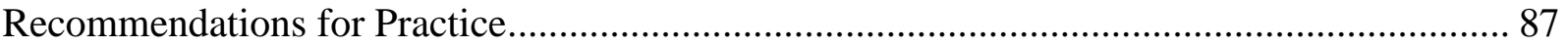

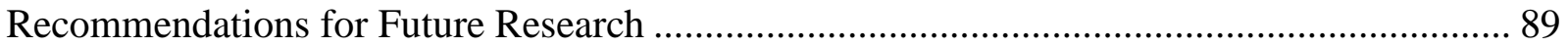

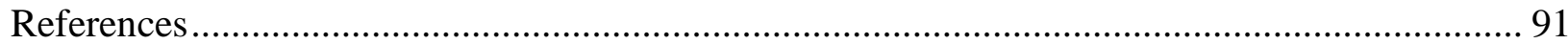

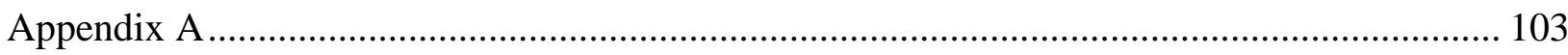

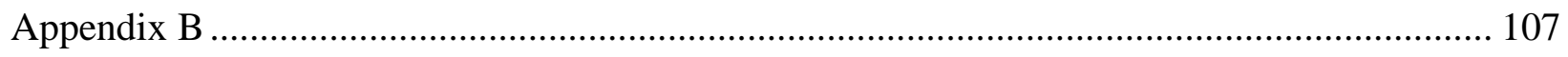

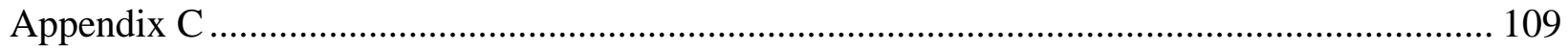

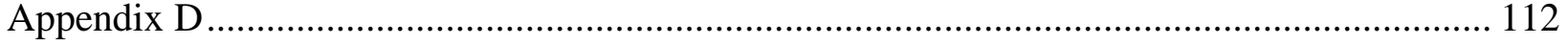

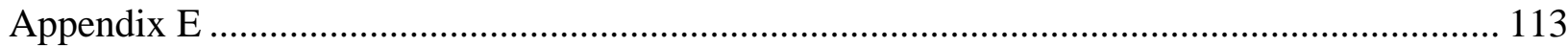

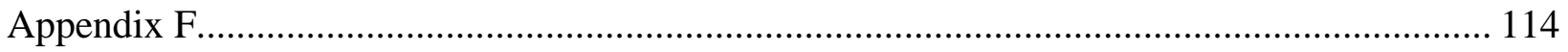

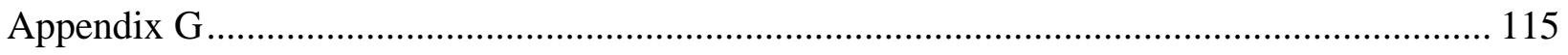




\section{Tables}

1. Comparison of Four Distributed Leadership Surveys............................21

2. Items of the Distributed Leadership Readiness Scale Mapped, by Dimension...........42

3. Comparison of Demographic Factors of Early and Late Respondents..................52

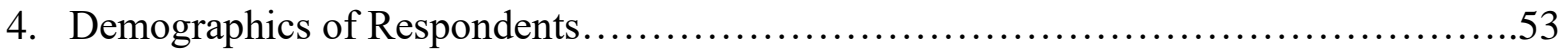

5. Distributed Leadership Readiness Scale Items Means and Standard Deviations..........55

6. Distributed Leadership Readiness Scale Dimensions, Mean with Item Numbers........60

7. School-Based Committee Influence Survey Means and Standard Deviations............61

8. Correlations of School-Based Committees and DLRS Dimensions.......................64

9. ANOVA Results for Gender and DLRS Dimensions.............................68

10. ANOVA Results for Years of Experience in Their School and DLRS Dimensions.......70

11. Post Hoc Comparison for Years of Experience in their School and Shared Responsibility................................................................ 71

12. Post Hoc Results for Years of Experience in School and Mission, Vision, and Goals....72

13. ANOVA Results for Programmatic Level and DLRS Dimensions....................73

14. Post Hoc Results for Programmatic Level and Shared Responsibility..................74 


\section{Chapter 1}

\section{Introduction}

Distributed leadership theory was developed from prior leadership theories partly due to increased demands on schools and leaders. The earliest schools in the United States of America did not have principals. As the one room school houses expanded to multi-classroom schools, the need for a principal also grew. Early principals were managers of the building, and many still had teaching duties. The Common School Report of Cincinnati of 1838 was one of the earliest written records of the term principal (Grady, 1990). It took another twenty-four years for the principal to lose his/her teaching duties and become a full time leader of the school (Grady, 1990). A century later, the principal was still working as a building manager, but political pressure in the United States and international competition pushed schools to be more inclusive and rigorous (Coleman, et al., 1966; United States Department of Education, 1983).

Because of the pressure on United States schools to be competitive worldwide, the educational research began to identify the need to implement effective leadership strategies. Researchers began to examine what made schools effective (Edmond, 1982; Lezotte, 1991). One crucial area of research was instructional leadership. This prompted many researchers to examine the topic in more depth (Blasé \& Blasé, 1999; Cotton, 2003; Hallinger \& Heck, 1996; Leithwood, Louis, Anderson, \& Wahlstrom, 2004) and also pushed principals to take ownership of the instructional leadership in schools (Sergiovanni, 1998).

Two reports helped to change the landscape of the United States of America's school system. The Equality of Education Opportunity Report (Coleman, et. al, 1966) and A Nation at Risk: The Imperative for Educational Reform (1983) ushered in an era of reform for schools. These reports opened the nation's eyes to the issues of equality and student performance within 
our school systems. Then in 2001 the Elementary and Secondary Education act was reauthorized and America's schools were officially pushed into the age of accountability.

At the start of the $21^{\text {st }}$ century, ground-breaking legislation, the No Child Left Behind Act, reauthorized the Elementary and Secondary Education act to bring sweeping changes to schools (United States Department of Education, 2002). This law brought the age of accountability to the forefront of America's schools. Accountability also brought consequences to low achieving schools. The impact on schools and principals was immediate. The critical need for change impacted all educational leaders (Leithwood, 2001) and leadership practices were put in the spotlight (Fullan, 2003).

Schools are at a point where the principal cannot effectively complete all the required tasks. Because one individual cannot meet all the demands of increased accountability, there is a need to distribute the leadership tasks as well as utilize the knowledge and strengths of their staff. By distributing leadership, principals can focus on the instructional priorities of the school. Research demonstrates that instructional leadership and strong leadership are critical parts of an effective school (Edmond, 1978).

For schools to be effective, principals must be engaged in the instructional process of the school. This engagement is just one of the many tasks that principals are required to accomplish during their busy schedules. The distribution of leadership is necessary for principals to accomplish their goals. The research on distributed leadership shows how it can impact a school. A qualitative case study by Ouchi et al. (2003) found that the high-performing schools had staffs which shared the responsibility for student outcomes, and there were more site-based management systems in place. Copland (2003) found that after a three year period of the distribution of leadership across the organization, the trend of the student achievement was 
positive. Yet, Spillane et al.'s $(2001,2004)$ work on distributed leadership showed that focusing on leadership improvement with only the formal leader of the school did not produce the best results for school improvement.

In recent years, the research has provided more empirical studies that are being used to determine the impact of distributed leadership on schools. Much of this research focused on the impact of distributed leadership on student achievement, and five studies showed a positive relationship between distributed leadership and student achievement (Gordon, 2005; Davis, 2009; Hallinger \& Heck, 2010; Onukwugha, 2013; \& Phillips, 2013). Other researchers looked at different aspects of the school and whether distributed leadership had an impact (Christy, 2008; Hulpia, Devos, \& Van Keer, 2009; Zinke, 2013). This study contributes to the literature on distributed leadership by examining if the school-based committees in place can have a perceived influence on the distributed leadership of a school.

Today's principals are asked to do more than ever in their schools. Additionally, principals are also held accountable for the student learning and achievement outcomes of the school. No longer are principals expected to only manage the staff and building, they are ultimately responsible for the climate and culture of the school, staff, student achievement, student attendance, student behaviors, and the school buildings. Increased expectations have created a situation where principals cannot do it alone. Distributed leadership allows for the use of the expertise and abilities of more than one person. For schools to succeed, they need to have a team of leaders working toward a common goal.

Distributed leadership studies show that it can have a positive influence on a school. This leadership model can provide additional help to principals to complete their multitude of leadership and managerial tasks. By including others in the leadership process, the collective 
knowledge of the group can be used to benefit the school. Empirical research on distributed leadership is also limited and many of these studies focus on a link to student outcomes (Broudreaux, 2011; Davis, 2009; Gordon, 2005; Phillips, 2013; Rivers, 2010; Zinke, 2013).

In West Virginia, statutes and policies grant authority to seven school-based committees which can contribute to the decision-making process of various aspects of the school. While the intent of these laws was not to implement distributed leadership into West Virginia schools, leadership opportunities were granted to each school-based committee. No research studies could be found which examine any of these school-based committees influence leadership in West Virginia Schools.

\section{Statement of Problem}

This study sought to determine the relationship between the distributed leadership readiness of West Virginia principals and their perceptions of selected school-based committees which influence leadership in their schools.

\section{Research Questions}

1. What is the distributed leadership readiness of West Virginia principals?

2. What are West Virginia principals' perceptions of selected school-based committees which influence leadership in their schools?

3. What is the relationship between the distributed leadership readiness of West Virginia principals and their perceptions of selected school-based committees which influence leadership in their schools?

4. Is there a difference between specific demographic characteristics of principals and their distributed leadership readiness? 


\section{Research Design}

Three categories of data were requested from the 674 principals in West Virginia for this study: demographic variables, distributed leadership readiness, and perception data about the influence of West Virginia school-based committees on leadership in their schools.

Demographic data include: gender, years' experience in education, years' experience in the school and programmatic level. Data was collected using the Distributed Leadership Readiness Scale (DLRS), developed by the Connecticut Department of Education in 2002 (Gordon, 2005) to collect distributed leadership readiness of West Virginia principals. The School-Based Committee Influence Survey was developed to measure principals' perceptions about the influence of specific school-based committees on the leadership of the school.

This study utilized quantitative data to attempt to answer each of the proposed research questions. To address the first research question, the means and standard deviations for the items of the DLRS and the four dimensions were calculated. The means and standard deviations were used to find the distributed leadership readiness of the principals. For the second question, the means and standard deviations from the School-based Committee Influence Survey were calculated for each item. The means and standard deviations were used to find perceived influence of the selected school-based committees on the leadership of the school.

The third question examined if there was a relationship between the dimensions of the DLRS compared to the perceived levels of influence from the School-Based Committee Influence Survey. Lastly, the fourth question used an ANOVA to see if there is were any significant differences between specific demographic factors and the dimensions on the DLRS. 


\section{Significance of Study}

Successful schools are critical to preparing students for the challenges of a global society. Many politicians, researchers, school administrators, teachers and community members have participated in the process to improve schools. States and school systems have passed laws and policies that grant teachers and other school personnel the opportunity to participate in the decision making process. Distributed leadership research reveals that the formal leader needs help for meaningful school improvement to occur (Spillane, Halverson, \& Diamond, 2001).

In West Virginia, specific school-based committees give other stakeholders a chance to influence certain aspects of the school. These statutes and laws are providing distributed leadership opportunities for these school-based committees in West Virginia schools. This study sought to determine the relationship between the distributed leadership readiness of West Virginia principals and their perceptions of selected school-based committees which influence leadership in their schools. This knowledge can provide insight into the influence of these laws and policies, along with areas of focus which could improve distributed leadership in a school.

\section{Limitations}

For the purpose of this research, only principals were included in the study. By only surveying one person in each school, the data collected will not be a complete picture of the distributed leadership readiness of a school. The survey was sent out to principals during the month of July, when many were not working in their schools. This could have had a negative impact on the response rate of the survey. Also, participation in the study was voluntary and this may have caused an unequal number of responses for the selected demographic characteristics being used for the study. This survey depended on a self-report of the perceptions of the principals. 


\section{Definitions of Terms}

Distributed Leadership: "multiple sources of guidance and direction, following the contours of expertise in an organization, made coherent through a common culture. With its members holding the various pieces of the organization together in a productive relationship with each other, and holding individuals accountable for their contributions to the collective result. This requires concerted action among people with different areas of expertise and a mutual respect that stems from an appreciation of the knowledge and skill requirements of different roles" (Elmore, 2000, p. 15).

Distributed Leadership Readiness Scale: self-evaluation scale designed to provide a profile of a district/school's readiness in shared leadership practices. The scale is based on school leadership research and designed to help improve public school capacity to increase student academic achievement (Elmore, 2000).

Policies: A course or principle of action adopted or proposed by a government, party, business, or individual (Oxford Dictionaries Online, n.d.).

Principal: "a professional educator who functions as an agent of the county board and has responsibility for the supervision, management and control of a school or schools within the guidelines established by the county board. The principal's major area of responsibility is the general supervision of all the schools and all school activities involving students, teachers and other school personnel” (West Virginia Code $§ 18-1-1,2014$, Sec. C.2)

Programmatic Level: West Virginia defines three programmatic levels Early Learning (PreK-5), Middle Level (5-8), and Adolescent Level (9-12).

Readiness: the state of being fully prepared for something. 


\section{Summary}

This study sought to determine the relationship between the distributed leadership readiness of West Virginia principals and their perceptions of selected school-based committees which influence leadership in their schools. In the age of accountability, every aspect of the school must be examined to find how schools can provide the best possible education for students. Today's principals are searching for researched-based practices that could contribute to school success. Some believe that even a small increase in the use of distributed leadership in a school could lead to positive outcomes for students e.g., Spillane (2006).

The next chapter contains a literature review of conditions which create demands on our schools, leadership research which helped distributed leadership theory to develop, current distributed leadership research and a section on the laws in West Virginia pertinent to this study. Chapter Three will describe the research design, including the study sample, survey tools, data collection process, and data analysis. Chapter Four will include the results of the data collection process, data analysis findings and application of the findings to the research questions. Chapter Five will focus on the results by presenting conclusions of the findings and suggestions for future research. 


\section{Chapter 2}

\section{Review of the Literature}

\section{The Principal as a Leader}

The purpose of this study was to determine the relationship between the distributed leadership readiness of West Virginia principals and their perceptions of selected school-based committees which influence leadership in their schools. This section will cover these topics: historic roles of the principal, changing roles of the principal, leadership theories, emergence of distributed leadership, current distributed leadership research, instruments of distributed leadership, Distributed Leadership Readiness Scale, West Virginia statutes and regulations, and a summary. This study is based on the Distributed Leadership Readiness Scale and the body of work that has been developed from the scale.

Historic roles of the principal. Early schools were small, many only a single classroom, and managed by the teacher. As schools began to grow, head teachers and principal teachers were added to help in the management of the school. These expanded roles came about due to the growing number of students in schools and because grading was being implemented. The Common School report of Cincinnati of 1838 contained one of the earliest printed uses of the term principal (Grady, 1990). The addition of these administrative duties continued, and eventually all teaching aspects were eliminated from the job of the principal. The role of principal, without teaching duties, became the general trend in large cities around 1860 (Grady, 1990). Up until 1954, educational leaders worked to create American schools to meet the needs of the corporate society (Tyack \& Hansot, 1986). Due to a society becoming more diverse and 
complex, the principal job was redesigned (Tyack \& Hansot, 1986). This created a job scope with the primary focus of managing the building and the staff.

Changing roles of the principal. The role of the principal began to shift towards other tasks within the school, not just management. The publication of the Equality of Educational Opportunity Report by Coleman et al. (1966) pushed the United States to examine its schools after the successes of the Russian Space program. The Coleman report used student testing data to analyze education quality in 4000 schools. The findings prompted programs to be started during the 1960s and 1970s to provide better educational services for minorities, women, and those with disabilities. However, the push for increased capacity of educational leadership did not occur until the next decade.

In the 1980s, the effective schools movement began to change the role of the principal. Principals became educational resources and were relied upon for their educational expertise (Barth, 1986). By focusing on the instructional side of the school, principals were expected to provide high expectations for teachers and students. This also brought on the duties of supervising classroom instruction, monitoring school curriculum, and understanding student achievement (Barth, 1986). Ron Edmonds (1982) analyzed effective schools, and in his work he introduced the correlates of effective schools. Larry Lezotte (1991) built further upon the correlates, and many districts still use these correlates today. Both scholars listed instructional leadership as a correlate of an effective schools.

Ron Edmonds (1978) claimed that effective schools needed to have strong leadership, and this correlate of effective schools led to a call for principals to be more involved with the instruction. This enhanced focus on leadership increased the principal's responsibilities and made instructional leadership the priority. As instructional leadership moved up the priority list, 
more research on the topic emerged (Blasé \& Blasé, 1999; Cotton, 2003; Hallinger \& Heck, 1996; Leithwood, Louis, Anderson, \& Wahlstrom, 2004). Richard Andrews and Rodger Soder (1987) expanded the concept of instructional leadership to include four areas of responsibility. These four areas are 1) resource provider, 2) instructional resource, 3) communicator, and 4) visible presence in the school. With these areas established, the role of the principal continued to grow from a manager to an instructional leader. No longer could principals only worry about the running and operating of the school. Principals now needed to commit themselves to meet the needs of the school, and they must work to pursue a shared purpose (Sergiovanni, 1998). Instructional leadership responsibilities continued to expand as the research base continued to grow.

In 1983, the political forces reemerged with the publication of A Nation at Risk: The Imperative for Educational Reform. This report came out as America was responding to declining student achievement scores and pushing for more rigorous curricula in schools (United States Department of Education, 1983). This political climate of change continued with the adoption of one of the most impactful pieces of federal education legislation. The reauthorized Elementary and Secondary Education Act brought educators into the age of accountability with the No Child Left Behind (NCLB) initiative and instituted strict guidelines for school achievement (United States Department of Education, 2002).

NCLB required high accountability standards for schools and required that states use Adequate Yearly Progress measures to show whether schools were meeting the standards. Schools and districts which could not meet the standards were met with penalties that would allow their students to have School Choice. Students could attend a high achieving school in the district and receive tutoring or attend afterschool programs. This wide-reaching legislation 
brought a push for change on all educational leaders (Leithwood, 2001). The accountability standards brought about a new focus on school improvement, and this put the spotlight on school principals, along with their leadership practices (Fullan, 2003). Principals were now looking at the curriculum framework and standards, along with having to usher in new forms of student assessment (Leithwood, Louis, Anderson, \& Wahlstrom, 2004). Leadership was now being looked at in relation to school outcomes and "leadership for learning." A focus on outcomes led to researching the effects of leadership on organizational outcomes and made learning a priority (Leithwood, Louis, Anderson, \& Wahlstrom, 2004). After examining these issues for the last two decades, policymakers began to realize that effective principals can have a positive impact on our schools (Robinson, Lloyd, \& Rowe, 2008).

With the revelation that effective leaders are needed in our schools, our educational system has come to alter the expectations of a principal. The job has grown from a manager to now include instructional leader. Principals are tasked with the management of the school, collaboration and support of the staff, discipline of students, instructional leadership, communicating with parents and community liaison. The demands of the job do not allow for one principal to complete the tasks effectively. Many individuals in a school need to be responsible for the numerous instructional leadership tasks. An examination of past leadership theories is needed to understand how the distributed leadership theory was developed.

Leadership theories. Distributed leadership evolved from many educational leadership theories. The following theories contributed to the development of distributed leadership: Trait, Behaviorist, Contingency, Situational, and Transformational. Each has built upon each other to lead us to distributed leadership. 
Trait theory. Trait theory was one of the earliest leadership theories and focused on personality attributes of the leaders. The belief was that certain personality attributes were related to effective leadership. Galton (1892) researched leaders and found that leaders were extraordinary individuals. He found that the traits that leaders possessed could not be taught. Stodgill (1948) used a meta-analysis of early leadership studies. He discovered that when examining leadership, the interactions of the leader must also be examined with the situational variables. This research led to the behaviors of leaders being examined because leadership was being looked at differently (Bass, 1999).

Behaviorist theory. When examining leadership through this lens, the actions of the leaders are examined to see what impact they have on their followers (Onukwugha, 2013). Two prominent studies on this topic found that leaders' behaviors can influence their followers. Stogdill (1948) completed the first study at Ohio State University which showed that leaders who put consideration into decisions and could initiate structures could improve productivity and the satisfaction of their followers. The second study, conducted by Lunenburgh and Ornsein (2004) at the University of Iowa, provided landmark data by showing that leaders' behavior has an impact on the attitude and behavior of their followers. The findings from these researchers prompted the examination of a broader scope of how leadership was occurring. The focus on principal leadership was widened to see if other factors also influenced leadership.

Contingency theory. The contingency theory was developed to address the holes in the behaviorist theory. The behaviorist ideas lacked attention to context and situations in which leadership occurred (Northouse, 2007). Fiedler (1967) offered empirical generalizations about this theory that allowed for the interaction of leadership styles with situational factors. His approach was to look at many aspects including the situation, the tasks, the people and the 
organization. He concluded that leaders can steer these interactions and situations to fit their leadership style. This theory was utilized because it was the first theory to examine the situation and its impact on the leader's actions. Contingency theory was also an extension of trait theory. For leaders to be effective, their personal traits and the situation need to match (Onukwugha, 2013). Hersey and Blanchard worked with contingency theory and used it to create situational theory (Hersey \& Blanchard, 1969).

Situational theory. Situational Theory expands leadership to say that there is not one leadership style that is best, but that leadership must be adjusted due to the maturity level of the leader's followers. This is the first theory to add the importance of followers and the development that they bring to the organization. Along with this theory also came four leadership styles: delegating, supporting, coaching and directing (Hersey \& Blanchard, 1969).

Although situational theory added the importance of the followers, this theory still had some shortcomings such as not addressing the influence of demographic characteristics, the development levels of the followers, and the importance of followers' input into the organization (Yukl \& Becker, 2007). The weakness of situational theory was the lack of input of the other members of the organization whose involvement was critical which led theorists to develop transformational theory.

Transformational theory. Transformational leadership theory highlights the importance of the followers in the organization and the need for the leader to engage them in the organization (McGregor, 1978). Under this framework, followers are an integral part of the leadership process and their commitment to the organization (Northouse, 2007). To improve the organization, followers are engaged and inspired to share the common vision of the organization (Avolio, Walumbwa, \& Weber, 2009). Transformational leadership emphasizes that leaders 
inspire a shared vision, challenge the process, enable others to act and encourage the heart (Kouzes \& Posner, 2007). This theory brings many positive elements to leadership, but still includes some of the trait theory elements, such as the heroic person who has the personality traits to get followers to perform at their highest potential (Bass \& Riggio, 2006).

An organization is as good as the people within that collective group. By focusing on the inspiration and motivation of the followers, leaders can create a stronger organization. This theory continued the growth of leadership studies, but a critical piece was still not evident: the leader was still the one looked upon for leadership. Transformational theory brought many strengths to the field, but it still failed to expand the leadership opportunities of others in the organization. This expansion is vital to complete all the needed tasks, and the distribution of leadership across the organization allows for others to have a chance to lead.

\section{Emergence of Distributed Leadership}

Distributed leadership came about because of the increased demand on principals. Principals were called upon to do more within the school, especially in the area of student achievement. Leaders and researchers began to see the benefit of having others, especially teachers, work in leadership capacities to help the school to achieve its goals.

As the idea of having others act as leaders took form, leadership researchers and theorists began using the terms "shared," "democratic" and "distributed" leadership. These researchers then set out to define and mold the ideas behind these terms. Distributed leadership emerged from the various terms, and the researchers began to examine how this theory fit with what was already known about educational leadership.

During the time that the concept was refined and studied, a few researchers came to the forefront with their definitions of distributed leadership and their thoughts on its benefits. This 
early phase of research allowed distributed leadership to be separated from shared leadership. As the practice of distributed leadership spread, researchers began their studies in schools. This work helped to further the concepts of distributed leadership.

The early research focused on the development of the theory and definition of distributed leadership. The term was first used in a study that looked at how certain processes influenced a variety of formal and informal groups (Gibb, 1968). The true refining of the concept came about in the decades of the late 1990s and early 2000s as the research base was expanded. The work of Elmore (2000), Gronn (2002) and Spillane (2006) allowed the theory to be developed as early qualitative research studies began to be completed.

Distributed leadership may have evolved from transformational leadership, but both share similar characteristics of shared decision making and leadership involvement of others in the organization. The term distributed leadership was first used in 1968 by Gibb when he stated, "leaders and followers exchange roles and observation has shown that the most active followers initiate acts of leading" (as cited in Gronn, 2002, p 252). He described the organizational group and how group quality is contingent upon certain functions performed by the group (Gibb, 1968). The work on distributed leadership continued and was expanded by other researchers.

Katz and Kahn (1966) advocated sharing leadership because any person can become the leader of an organization, but effective leadership comes with the distribution or sharing of leadership. This practice can improve the organization, along with improved decision-making. The leadership needs of the $21^{\text {st }}$ century can no longer be filled by traditional leadership (Lipman-Blumen, 1996). The demands of $21^{\text {st }}$ century education expect principals to be experts in instructional leadership to help improve the performance of teachers and students in their schools (Robinson, Lloyd, \& Rowe, 2008). The ability to distribute instructional leadership with 
school staff allows empowerment and professional growth for the teachers of the organization, in hopes that instructional improvement will occur (Leithwood, Louis, Anderson, \& Wahlstrom, 2004).

The concept of distributed leadership involves delegation, along with an organization that will develop leaders (MacBeth, Oduro, \& Waterhouse, 2004). By allowing teachers to work in leadership capacities, they are able to work to influence the school culture and goals (Conley \& Goldman, 1994). Gronn (2002) recognized that distributed leadership is not new, but the definition of "distributed leadership" is new. The definition of "distributed leadership" has taken different forms, depending on the researchers. Elmore, Gronn, and Spillane's definitions were used most in the research reviewed for this study. Elmore (2000) focuses on collective knowledge of the group and how the group can guide the entire school. The common task or goal is what can allow the parts of the organization to work together. Gronn's focus is control of self-managing teams where the action of the group can allow for their expertise to be used together and create improved results over an individual (Gronn, 2002). Spillane's work took the focus to the relationships that the leader has with their followers, along with an examination of the interactions between them. For the purpose of this study, Elmore's definition will be utilized (2000, p. 15):

This model focuses on the collective knowledge of the group and how that knowledge can be used for the impact of the entire school. The group is responsible for finding failure in isolated practice and finding success in the creation of interdependencies that stretch over these differences. Multiple sources of guidance and direction, following the contours of expertise in an organization, made coherent through a common culture. It is 
the 'glue' of a common task or goal (improvement of instruction) and a common frame of values for how to approach the task.

\section{Current Distributed Leadership Research}

Spillane et al.'s $(2001,2004)$ work on distributed leadership was funded by the National Science Foundation and the Spencer Foundation. It used a longitudinal design and focused on leadership practice. The goal was to examine the practices happening in schools and to give an in-depth analysis of the results. Using Spillane's framework of distributed practice, the study looked at how leadership was distributed over the social and situational contexts of the school. The research was conducted on 13 elementary schools in Chicago, and the researchers discovered that multiple leaders needed to be engaged in the process. This engagement allowed for a better understanding of the leadership practices of the school, and the interactions of the leaders proved to be essential. The researchers concluded that examining the whole school provided the best opportunity to view the development of leadership, rather than focusing on one leader. They also found that focusing on leadership improvement with the formal leader of the school does not produce the best results for school improvement.

The qualitative case study by Ouchi et al. (2003) compared analyses of central office budgets, accountability systems, and organizational structures of 232 schools in Edmonton (Canada), Seattle, Houston, New York, Los Angeles, and Chicago. Along with budgets and structures, they examined certain student performance measures, including standardized test scores and graduation rates. The study also used interviews and classroom visits to collect more insight into what was happening in the schools. They found that the high-performing schools had staffs which shared the responsibility for student outcomes, and there were more site based management systems in place. 
Copland (2003) conducted a study that examined 86 improving schools with reform efforts focused on data-driven decisions. These schools had also worked to distribute the leadership with various members of the staff to improve engagement in the reform process. The results of the study showed that the engagement of the staff improved the leadership and allowed for more involvement of the staff in the decision making of the schools. During this multi-year study, the limited data did not allow for definitive proof of an impact on student test scores. Yet after the third year, the trend of the student achievement was positive and was attributed to the distribution of leadership across the organization.

In recent years research provided more empirical studies which are being used to determine the impact of distributed leadership on schools. Much of this research has focused on the impact of distributed leadership on student achievement. A few studies have shown significant correlations between distributed leadership and student achievement, but a consistent link has not been established.

Gordon (2005) and Onukwugha (2013) found significant differences between the levels of the distributed leadership dimensions in high-performing and low-performing schools. Gordon (2005) also found that a school culture may be considered a statistically significant factor in predicting student achievement. Davis (2009) found a significant relationship between distributed leadership and mathematics and reading performance. Hallinger and Heck (2010) determined that a positive change in collaborative leadership was significantly related to the growth in academic capacity of a school. Lastly, Phillips (2013) found that there was a significant statistical relationship between teachers' perceptions of distributed leadership and the International Baccalaureate schools' academic performance. 
Other researchers looked at different aspects of the school and whether or not distributed leadership had an impact on any of those aspects (Christy, 2008; Hulpia, Devos, \& Van Keer, 2009; Zinke, 2013). One examined distributed leadership readiness in elementary schools compared to middle schools, with the results showing elementary schools more ready for distributed leadership (Christy, 2008). Researchers also examined the impact of distributed leadership on the organizational commitment of teachers. The results showed that cooperation from the leadership team, along with strong support, are the most important predictors for teacher organizational commitment (Hulpia, Devos, \& Van Keer, 2009). Finally, Zinke (2013) found that there was a significant relationship between distributed leadership and teacher selfefficacy.

The results of these studies show that distributed leadership may have some positive effects in schools. Distributed leadership is a model that could make a difference in a school. One aspect of these studies is the ability to measure the level of distributed leadership in a school. However, there are only a few instruments that have been developed. These instruments are varied, but one continues to be used consistently.

\section{Instruments for Distributed Leadership}

While examining the various studies, four different instruments were found to measure distributed leadership. Each instrument is examined in this section by, purpose, factors/dimensions, validity/reliability, and studies in which it was used. Table 1 below shows the attributes of each survey. The first three instruments were used in only a few studies, but one instrument was used extensively. 


\section{Table 1}

Comparison of Four Distributed Leadership Surveys

\begin{tabular}{|c|c|c|c|c|}
\hline Survey & Purpose & Factors/Dimensions & Validity/Reliability & Studies \\
\hline \multirow[t]{2}{*}{ LDI } & $\begin{array}{l}\text { leadership density of } \\
\text { a school }\end{array}$ & $\begin{array}{l}\text { leadership density; Student } \\
\text { leadership density; leadership }\end{array}$ & Yes/Yes & 2 \\
\hline & & opportunity (3) & & \\
\hline \multirow[t]{2}{*}{ DLI } & $\begin{array}{l}\text { Perceived quality of } \\
\text { leadership and the }\end{array}$ & $\begin{array}{l}\text { setting a vision; developing } \\
\text { people; supervising teachers }\end{array}$ & Yes/Yes & 1 \\
\hline & extent of distribution & (3) & & \\
\hline \multirow[t]{2}{*}{ DLS } & $\begin{array}{l}\text { Teacher perceptions } \\
\text { of the dimensions of }\end{array}$ & $\begin{array}{l}\text { school organization; school } \\
\text { vision; school culture; }\end{array}$ & Yes/Yes & 2 \\
\hline & $\begin{array}{l}\text { distributed } \\
\text { leadership }\end{array}$ & $\begin{array}{c}\text { instructional programs; } \\
\text { artifacts; teacher leadership; } \\
\text { principal leadership (7) }\end{array}$ & & \\
\hline \multirow[t]{2}{*}{ DLRS } & $\begin{array}{l}\text { Distributed } \\
\text { leadership readiness }\end{array}$ & $\begin{array}{l}\text { mission, vision, and goals; } \\
\text { school culture; leadership }\end{array}$ & Yes/Yes & 9 \\
\hline & of a school & $\begin{array}{l}\text { practices; shared } \\
\text { responsibility (4) }\end{array}$ & & \\
\hline
\end{tabular}

Note. LDI = Leadership Density Inventory; DLI = Distributed Leadership Inventory; DLS = Distributed Leadership Scale; DLRS = Distributed Leadership Readiness Scale

The Leadership Density Inventory is an early instrument that examined leadership density in schools developed by Smith (2001) for his dissertation. It was then refined to its current form by Smith, Ross, and Robichaux (2004). Leadership density is explained by how 
many potential leaders there could be in a school, while realizing that each school would be different due to the makeup of the staff. The inventory uses musical metaphors as its foundation and examines small groups working with the overall organization. Three factors of leadership density are used in the survey: leadership density, student leadership density, and leadership opportunities. The instrument was found to be valid and reliable by the developers (Smith, Ross, \& Robichaux, 2004). This instrument was then used in a dissertation by Jacobs (2010), where he studied distributed leadership practices of principals and the organizational commitment of teachers. His study found a moderate, positive statistical relationship between the two.

A second instrument is the Distributed Leadership Inventory (DLI) developed by Hulpia, Devos, and Rossell (2009). It was designed to measure the perceived quality of the leadership and the extent to which it is distributed. For the instrument, distributed leadership-contains three parts: setting a vision, developing people, and supervising teachers' performance. The instrument has been found to be valid and reliable by its developers (Hulpia, Devos, \& Rosseel, 2009). This instrument was used in a later study to examine the influence of distributed leadership on teacher organizational commitment and the study found that a cooperative leadership team can have a positive influence on a teacher's commitment to the school (Hulpia, Devos, \& Van Keer, 2009).

Davis (2009) developed an instrument using questions from other survey tools and called it the Distributed Leadership Survey. This survey was developed using items from three different scales: the Distributed Leadership Readiness Scale (DLRS), the Teacher Leadership Survey, School Leader Questionnaire, and items developed by the author. This scale measures teachers' perceptions about the seven dimensions of distributed leadership: organization, school vision, school culture, instructional program, artifacts, teacher leadership and principal 
leadership. Davis conducted a study to establish its validity and reliability. Once these measures were determined, she then used the tool to measure perceived quality of leadership and the extent to which leadership was distributed in the schools in her study. She found that higher Distributed Leadership Survey scores had a positive, significant relationship with third grade mathematics scores on the Maryland School Assessment test. One other study used this survey to examine the relationship between distributed leadership and high-stakes testing. This study found that three dimensions of distributed leadership (school culture, teacher leadership and principal leadership) had a positive, significant relationship with English-language arts scores on the Louisiana state standardized assessment (Broudreaux, 2011).

The most widely used instrument is the DLRS, a scale was developed by the Connecticut State Department of Education (CSDE) in 2005 to measure a school's readiness in distributed leadership. The instrument was based on the work of Richard Elmore's (2000) Building a New Structure for School Leadership, but was fully developed by using focus groups of teachers and administrators in Connecticut. In the original form, the instrument categorized distributed leadership into five dimensions: mission, vision and goals; school culture; decision-making; evaluation and professional development; and leadership practices. According to Jacobson (personal communication, April, 23, 2014), one of the instrument's developers, the survey was originally designed to help principals and teachers gauge their school's involvement in shared leadership practices.

The original instrument was developed to be used by the CSDE in a pilot study of four schools. Gordon (2005) worked closely with the CSDE and was the first to use the DLRS in a larger study of 36 schools in Connecticut, 15 of which were designated as needing improvement by NCLB. The other 21 schools were part of the Connecticut Urban Leadership Academy. 
Gordon determined that the survey was valid and reliable. Construct validity was established using factor analysis. The internal consistency and reliability were tested using Cronbach's alpha correlation and all the dimensions have a reliability coefficient of .84 or higher. These values were above the recommend value of a reliability coefficient of .7 and determined the survey to be reliable. Due to the results of the factor analysis, a change made was reducing the number of dimensions from five to four. The resulting four dimensions and forty items were validated by the empirical factor analysis. All the items had a factor loading of.35 or above, thus establishing validity. The entire survey was proven to have strong construct validity and reliability (Gordon, 2005).

\section{Distributed Leadership Readiness Scale}

The Distributed Leadership Readiness Scale measures the readiness of distributed leadership in a school with four dimensions. Readiness measures how prepared schools are to implement distributed leadership. The research of Gordon (2005) combined two dimensions: 1) decision-making and 2) evaluation and professional development, into shared responsibility. This resulted in an instrument with four dimensions: 1) Mission, Vision, and Goals, 2) School Culture, 3) Shared Responsibility, and 4) Leadership Practices. Each dimension contains at least eight questions, and this section will expand upon each dimension.

The first dimension, Mission, Vision and Goals, is used by many when discussing educational leadership. Elmore (2000) defined educational leadership as the tasks aimed at improving instruction. The Mission, Vision and Goals are described as the building blocks of an organization by DuFour and Eaker (2008). They also state that these three criteria help to engage the faculty in the decision-making process. Hallinger and Heck (2010) wrote that by implementing a mission, vision and goals, school leaders can guide teachers and provide learning 
opportunities for students. Finally, Harrison (2008) explained that organization members need to share a vision and work toward common goals. With the emphasis on these three items, school leaders must remember that, to be effective, the stakeholders need to know the mission, vision and goals. They also must be current and reflective of the values of the school and district (Gordon, 2005).

The second dimension is School Culture. Elmore (2000) identified school culture as a dimension of leadership and acknowledged the influence it could have on student achievement. An organization's culture is how its traditions, customs and behaviors add to its general way of life (Saphier \& King, 1985). A school's culture is created over time and can influence many aspects of a school (Gordon, 2005). A positive culture in a school can add a sense of purpose, along with providing improvement and learning for staff and students (Sally, 2002). A school with a negative culture can experience the opposite effects and see a decrease in student learning and performance (Sally, 2002). The role of culture in a building can easily be overlooked due to the busy nature of a school, but all aspects of the school can be impacted by a positive culture (Saphier \& King, 1985).

The third dimension, Shared Responsibility, is broad due to two dimensions being combined into one. Decision-making is a process that happens in schools every day. School reform efforts have pushed schools to make data-driven decisions that can be measured. Waters et al. (2003) performed a meta-analysis of school improvement research studies and found that involving teachers in important school decisions had a measurable impact in student achievement. Evaluation and professional development are also vital aspects to school growth and can help to improve innovation and teacher confidence (Shannon \& Bylsma, 2007). To help this growth and to make professional development effective, it must be systematic, research- 
based, and ongoing (National Staff Development Council, 2001). Ellerbee and Miller (2000) determined that well-organized professional development activities can increase student achievement for a school.

The final dimension is Leadership Practices. Gordon (2005, p. 41) defined this dimension as "how school leaders define, present and carry out their interaction with others in the process of leading." The way a school leader uses these practices can shape school structures and can have a great influence on the teachers and learning practices of the school (Halverson, 2004). Once these leadership practices can be effectively used for leadership distribution, then this can allow for the sharing of power and responsibility across the organization (Harris, 2007). It should be noted that a leader who decides to hold on to all the power and decision-making creates barriers to distributed leadership (Hatcher, 2005).

The DLRS, or some of its questions, have been used in other studies. Christy (2008) used the DLRS to examine distributed leadership and programmatic levels with the four dimensions determined by Gordon (2005). Her study examined distributed leadership readiness in elementary and middle schools. Her findings show that elementary school staffs had a higher readiness in distributed leadership than the middle school staffs.

Zinke (2013) studied shared leadership, teacher self-efficacy and student achievement. The study used the DLRS with the four dimensions determined from Gordon (2005) to measure shared leadership, the Teacher's Sense of Efficacy Scale (TSES) to measure teacher selfefficacy, and the Mississippi Curriculum Test, Second Edition (MCT2) was used to measure student achievement for third graders. Correlational analysis determined that there was a "small to moderate significant linear relationship between the dimensions of distributed leadership and the subscales of teacher self-efficacy" (Zinke, 2013, p. 89). The study found no significant 
relationship between teacher self-efficacy and student achievement on the MCT2 (Zinke, 2013).

No analysis was done between distributed leadership and student achievement.

Rivers (2010) was another study examining distributed leadership and student

achievement. The study used the DLRS and the original five dimensions, despite the work of Gordon (2005) determining four dimensions after her testing for validity. The results of the DLRS were used, along with student achievement data from the Palmetto Academic Challenge Test (PACT) for third graders. The study compared PACT results for two consecutive years. The first year was without distributed leadership, and second year was with a distributed leadership implementation in the school. The results of the implementation showed gains in math and significant growth in reading. Rivers concluded from the DLRS results and the PACT gains that distributed leadership is an effective strategy (Rivers, 2010).

Onkwugha (2013) conducted a study that examined distributed leadership, teacher practices and student learning. These were studied in schools with small learning communities, and the study was a qualitative case study. This unique study used the DLRS, with the 5 original dimensions, as a check list to review case studies and looked at high- and low-performing schools (HPS \& LPS). The DLRS was used to analyze and extrapolate data from fifty case studies which studied distributed leadership. The study examined the implementation of distributed leadership related to school performance and student learning. It also examined teacher leadership practices related to school performance.

The results of the study showed a "significant difference in the implementation of distributed leadership in both HPS and LPS" (Onukwugha, 2013, p. 152). Teachers' practices in the schools showed both high-performing school and low-performing teachers were able to "translate the curriculum in their classroom" (p. 154). There was a difference in standards based 
curriculum with most of the HPS schools engaged in the practice, while about one-half of the LPS were engaged. Teachers at the HPS used data driven instruction, and the LPS teachers were not fully engaged. Onukwugha concluded that the study showed a significant difference in the DL practices of the HRS and LPS schools. Also distributing leadership among teachers "might have served as a mediator for high student achievement in HPS" (p. 156).

Davis (2009) examined the relationship between distributed leadership and elementary school performance. In her study, distributed leadership was measured with the Distributed Leadership Scale which was developed by the author and included questions from the DLRS. The student achievement data was from the Maryland School Assessment tests for mathematics and reading for third graders. The results showed a statistically significant relationship between mathematics scores and distributed leadership. One dimension had a positive statistically significant relationship with the reading performance, and three other dimensions had a positive statistically significant relationship with mathematics performance.

Broudreaux (2011) set out to investigate the relationship between distributed leadership and student achievement. She also used the Distributed Leadership Scale. The results of this scale were used in a bivariate correlational analysis with the English-language arts and math results of the Louisiana Educational Assessment Program (LEAP). Three dimensions of distributed leadership (school culture, teacher leadership and principal leadership) showed a positive statistically significant relationship with the LEAP English-language arts assessment results.

Phillips (2013) studied distributed leadership and academic performance of International Baccalaureate (IB) World Schools. To complete the study, Phillips created the IB World School Distributed Leadership survey from the Distributed Leadership Survey and the DLRS. School 
Performance data was collected from the IB Diploma results. The results showed a positive statistical relationship between the teachers' perceptions of distributed leadership and the IB schools' academic performance.

In the previous reviews of the DLRS usage in research, the intent and results have been varied. Six of the seven studies used the instrument to examine distributed leadership and any relationship to student achievement. In five of the studies a significant relationship was found between the distributed leadership dimensions and student achievement. These results show the potential of distributed leadership to have an influence on the student outcomes of a school.

\section{West Virginia School-Based Committees}

This section will review relevant West Virginia statutes and policies which create school-based committees that allow for teacher involvement in specific leadership processes in the school. Seven school-based committees have been granted leadership in schools. The seven include the following: faculty senates, professional development councils, school curriculum teams, local school improvement councils, five-year strategic planning committees, mentor teachers, and school technology teams. For each group, a review of the specific code or policy extending the leadership, why the code or policy was established, who can be a member, its purpose and the group's role in the school will be discussed.

Faculty senates are found in West Virginia Code $§ 18-5 A-5$ and West Virginia State School Board Policy 2510. These groups were created during a special summer legislative session in 1990 and were an outcome of the 1990 West Virginia teacher strike (Rice \& Brown, 1994). The faculty senate of each school is made up of the permanent full-time professional educators employed at the school, and each employee is a voting member. Each faculty senate is assigned control of funds allocated to the school, and these funds must be used for academic 
materials and supplies. They may also solicit, accept, and expend any grants, gifts, bequests, donations or any other funds made available to them.

The faculty senate may nominate teachers for recognition as outstanding educators, establish a process to review sabbatical leaves, provide suggestions on scheduling of service personnel, and review the school evaluation process. They also submit recommendations for master curriculum, shall provide an opportunity for the recommendations of beginning teacher mentors, and the spending of various funds under their control. This group can also provide members for the local school improvement council and the county staff development council. Lastly, each faculty senate shall establish a strategic plan for the integration of special needs students into regular education classrooms (West Virginia Code §18-5A-5, 2014; West Virginia Board of Education, 2014). Faculty senates are mandated to meet once prior to the instructional term and four more times, for a two hour block, at least once every 45 instructional days.

In 2013, faculty senates were given the option to be a part of the hiring process due to West Virginia Code §18-5A-5. This code was passed during the 2013 legislative session and was included in Senate Bill 610. A faculty senate may elect to establish a process to participate in the hiring process for classroom teacher vacancies in the school. Members participating in interviews must be trained, follow all timelines, follow all ethics rules and be compensated if the participation takes place outside of their normal contract. The faculty senate may also delegate the process to a committee of no less than three members to make the recommendation (West Virginia Code $\$ 18-5 A-5,2014)$.

Professional development councils are found in West Virginia Code §18A-3-8. The code specifically states, "The Legislature finds the professional expertise and insight of the classroom teacher to be an invaluable ingredient in the development and delivery of staff development 
programs which meet the needs of classroom teachers" (West Virginia Code §18A-3-8, 2014).

The council is a proportional representation of the programmatic levels of the county and should include any specialties (vocational, special education and any other area). Each council should be between nine and fifteen members, and they have the final authority for the county's staff development proposals (West Virginia Code §18A-3-8, 2014).

School curriculum teams can be found in West Virginia Code $§ 18-5 A-6$ and were created to allow teachers to be part of the process to improve student learning. This team is composed of the principal, the counselor, and no fewer than three teacher representatives. This team shall have a direct voice in the operation of their school and work to create a culture of shared decision-making focused on raising student achievement. Their powers and duties include curriculum implementation, assessments, instructional strategies, and other curricular based decisions (West Virginia Code $§ 18-5 A-6,2014)$.

Local school improvement councils (LSIC) are found in West Virginia Code §18-5A-2. The LSIC reviews discipline data and procedures yearly, then submits written recommendations to the local school board. The LSIC encourage involvement of the school community with the operation of the school through regular LSIC meetings and collaboration. They support local initiative for school improvement by being directly involved with the strategic planning and innovative ideas. The LSIC is made up of the principal, three teachers elected by the faculty senate, one bus driver, a service person elected by the school service personnel, three parents, guardians, or custodians of students enrolled at the school elected by the parent organization, and two at-large members appointed by the principal. If the school has a vocational-technical component, the director will be a member of the LSIC. Lastly, in schools with students in grade 
levels 7-12, the student body president or another student elected by their peers will serve (West Virginia Code $§ 18-5 A-2,2014)$.

The LSIC shall met to work on "effective discipline policies for the school” (West Virginia Code $§ 18-5 A-2,2014)$. They will also review all discipline at the school and examine it for fairness and consistency. They are required to report any issue to the county superintendent. They should also meet with the county board of education to provide any information, comments or suggestions. This group is also given the authority to encourage the involvement of parents and guardians in their child's educational process, encourage businesses to provide time to parents or guardians to meet with their child's teachers, encourage advice and suggestions from the business community, encourage school volunteer programs, and foster utilization of school facilities and grounds for public community events (West Virginia Code §18-5A-2, 2014). The LSIC must meet each year before October 1 and then meet at least once every instructional term. The school leadership team is defined in West Virginia State Board of Education Policy 2510. This team is responsible for creating the electronic school strategic plan in West Virginia Code $§ 18-2 E-5(b)$. This plan, also referred to as the five-year strategic plan, should address the identified needs of the school and strategies to improve student achievement with a continuous improvement process. The team's responsibilities include: analyze student performance data; review all facets of the school's operation; review monitoring reports relevant to school improvement; use self-study tools to determine priorities for improvement; determine causes of deficits in student performance and make recommendations for improvement; collaborate with parents, staff, and county team to identify school improvement goals, plan, implementation and monitoring; recommend additional assistance to implement the school improvement plan; and collaborate with outside entities to address student learning needs. This team includes 
representatives from the LSIC, the curriculum team, the technology team, professional learning communities and parent/community organizations. The team should meet annually to revise the plan to adjust for current assessment data, any available monitoring reports, and changes in the school (West Virginia Board of Education, 2014).

Teacher mentors, master teachers and academic coaches are included in the teacher induction and professional growth section of West Virginia State Code WV State Code §18A$3 \mathrm{C}-3(\mathrm{j})(\mathrm{d})(5)$. The law is designed to allow for support of beginning teachers in West Virginia. Mentors, master teachers, or academic coaches may provide support, supervision or other professional development to employees for the purpose of improving their professional practice. These positions would be selected on criteria in which they have shown superior performance and competence in the classroom (West Virginia Code §18A-3C-3, 2014).

The school technology team is required in West Virginia State School Board Policy 2460, section 5.7.b. This team is also mentioned in West Virginia State School Board Policy 2510, section 7.3.q and 7.3.v. The team is required to develop a comprehensive technology plan that is part of the five-year strategic plan. Schools have the option to have the LSIC, faculty senate or the school curriculum team serve as the technology team. The only duty assigned to the team in Policy 2460 and 2510 is to develop a comprehensive technology plan. The policy does not define who should be on the technology team, nor does it define a comprehensive technology plan (West Virginia Board of Education, 2012; 2014).

Each of these seven areas provide tools which distribute leadership in schools. The teachers or stakeholders are granted authority to make decisions and have input into various aspects of a school. This distribution does create processes which can assist schools in developing a model of distributed leadership. The committees created can be used by the school 
principal to distribute leadership, but the principal still plays an integral role in creating a distributive environment (Hallinger \& Heck, 2009b)

\section{Summary}

In the early years of school leadership, principals were responsible for managing their schools. The current role of principals has changed in the past 180 years. Today's principals are still asked to manage their buildings along with being instructional leaders. With the added demands of the accountability movement which have swept through our schools, the principal's tasks have increased greatly. These demands have added responsibility to the job and created more tasks than can be completed by one individual.

Leadership theories have also evolved since the introduction of trait theory. Researchers found that the followers of an organization were important to the leadership of the organization (Northouse, 2007). This led to the theory of distributed leadership and its importance. Elmore (2000) describes distributed leadership as using the collective knowledge, guidance, and direction of the group to help impact the school. This idea of distributing leadership roles and tasks to others in the organization allows for more expertise working on the common goals of the school. To allow for input and involvement from the followers of an organization, leaders build upon the collective knowledge of the group. This collective knowledge and distribution of work allows the principal to complete the many demands on his or her plate

In West Virginia, multiple statutes and policies have been implemented to include teachers and other stakeholders in various school-based committees of the school. They have a wide range of decision-making influence from curriculum to the hiring of teachers. These statutes and policies have been passed and modified over the last few decades. Granting authority to these committees can allow for the distribution of leadership. 
Distributed leadership researchers have completed multiple studies to find what impacts this leadership theory can have on a school. These studies have shown that distributed leadership can influence teacher efficacy to various student outcomes (Boudreaux, 2011; Davis, 2009;

Hulpia, Devos, \& Van Keer, 2009; Onukwugha, 2013; Smith R. W., 2001). Hallinger and Heck (2009b) looked at the role of principals in environments when the distribution of leadership was inserted into statute. They found that when distributed leadership was included in policy, principals still had a critical leadership role to be filled for school improvement. This research intended to start the examination in West Virginia by looking at principals' perceptions of the leadership enacted by the various statutes and policies in relationship to the distributed leadership readiness of their schools. 


\section{Chapter 3}

\section{Research Design}

\section{Introduction}

This chapter discusses the research design used to determine the relationship between the distributed leadership readiness of West Virginia principals and their perceptions of selected school-based committees which influence leadership in their schools. This chapter contains the research rationale, research theoretic, study population, demographics, research procedures, Distributed Leadership Readiness Scale, School-Based Committee Influence Survey, data collection, data analysis, and a summary.

The study sought to answer these research questions:

1. What is the distributed leadership readiness of West Virginia principals?

2. What are West Virginia principal's perceptions of selected school-based committees which influence leadership in their schools?

3. What is the relationship between the distributed leadership readiness of West Virginia principals and their perceptions of selected school-based committees which influence leadership in their schools?

4. Is there a difference between specific demographic characteristics of principals and their distributed leadership readiness?

\section{Research Rationale}

This section addresses two areas of research design: first quantitative and qualitative research will be briefly reviewed, and second, the reason for choosing the research method for this study. The next area of focus for this section is the study population, along with specific research on the demographic factors being used in this study. 
Research Theoretic. Research design allows for structure in the research process of data collection and analysis. Conclusions can then be drawn about the subject being studied (Field, 2005). Two methods of research are used in educational studies. The first is quantitative research methods which is used to collect numerical data from experiments, rating scales and closed questioned questionnaires (McLeod, 2008). The data collected can be used for statistical analysis, which then allows for conclusions to be drawn from the results (Creswell, 2008). Qualitative research collects descriptive, non-numerical data, through the process of observations and interviews (Glense, 2006). The researcher is immersed into the data collection process and the collected data is examined for patterns (Glense, 2006).

This study utilized a quantitative design to attempt to answer each of the proposed research questions. By using this approach, the study was able to test relationships between variables with statistical analysis. Quantitative methods were used to attempt to present results which can be generalized and replicated for further study of the topic (Creswell, 2008). The design used two survey instruments to collect data. One instrument was the DLRS to measure the distributed leadership readiness of West Virginia principals. A second instrument, the School-Based Committee Influence Survey, was developed to be used with the same group of principals. This second tool was based on seven school-based committees as found in West Virginia statutes and State Board of Education policies as described in Chapter 2. This instrument collected the perceptions of the principals on the influence of the school committees. The instruments were presented to principals as one questionnaire, and it also collected specific demographic data. This data was analyzed with the distributed leadership readiness to examine the relationship, if any, between the two variables. 
Study Population. The selected population for this study were the principals of the 674 schools in West Virginia. In West Virginia, the schools are classified by their programmatic level. There are three programmatic levels. According to West Virginia School Board Policy 2510, these levels are defined as Early Learning (PreK-5), Middle Level (5-8), and Adolescent Level (9-12). The breakdown of all the schools in West Virginia being used for this study is early learning (412), middle level (151), and adolescent level (111). By surveying the principals from each of these classifications, the data collected was able to be analyzed with the specific demographic data collected.

Demographics. This study also examined demographic characteristics of principals and their associations with their distributed leadership readiness. Distributed leadership studies were reviewed for findings with any demographics. The characteristics are gender, years of experience, and programmatic level.

Gender. The gender of a principal was found to be significant in a quantitative study by Grant (2011). Part of his study sought to find if any of five demographics characteristics had an effect on distributive leadership in schools. He had positive correlational findings for one demographic characteristic with two of his defined distributive leadership functions. The first distributive leadership function was managing the instructional program. For this function, he found that male principals were more likely to administer this function for distributive leadership in schools. The second function with a relationship was developing people, and he found that females were more effective (Grant, 2011).

Years of Experience. The years of experience of a principal was found to be significant by two distributed leadership studies conducted by Leung (2008) and Marie Gibson (2012). Leung (2008) found that for the seven dimensions of distributed leadership used in her 
quantitative study, only three showed any effects when compared to demographic variables. This effect was limited to three factors of her ten demographic data collected. She found that principals with more experience distribute more tasks within the dimension of Teaching, Learning and Curriculum than principals with less experience. In the same dimension, she found that principals with the least experience in their current schools distribute tasks less than principals with more experience in their current school. The last factor to show an effect was for principals appointed internally from within their school. This factor showed that these principals distribute Staff Management tasks less than principals appointed externally. Gibson (2012) conducted a qualitative study and found a significant result when examining a principal's experience level. Gipson-Francis found that the level of task distribution increases with a principal's experience as a principal.

Programmatic level. The programmatic level of the school where the principal serves was studied by Christy (2008). Her study examined the distributed leadership readiness of principals at the elementary and middle school programmatic levels. Christy (2008) used the DLRS in her quantitative study and four dimensions of distributed leadership. The results of the study showed that elementary school certified personnel rated their school higher for all four dimensions of distributed leadership than the ratings of the middle school certified school personnel.

\section{Research Procedures}

Data was collected using the Distributed Leadership Readiness Scale (DLRS) along with the School-Based Committee Influence Survey to collect perceptions about selected West Virginia school-based committees. These committees were selected due to their potential influence on distributed leadership in schools. 
Distributed Leadership Readiness Scale. The DLRS was developed by the Connecticut State Department of Education in 2003 (Gordon, 2005). This scale was developed to determine a school's readiness of distributed leadership. It was based on then current research on school leadership and designed to improve public schools' ability to increase student academic achievement. Permission was granted by Larry Jacobson for us of the DLRS by this researcher (See Appendix F). Face validity was established by a committee of educators when they reviewed the items on the DLRS and the items were then assigned to one of the original five distributed leadership dimensions (Gordon, 2005). Face validity is when a group of experts in the field are asked to determine if the instrument appears to measure what it intended to measure.

In the initial DLRS study, two samples were used for the initial study. The first sample set included four schools participating in a distributed leadership initiative in northeastern Connecticut. Two of the schools were high performing and two were in the state's school improvement process. This initial use of the DLRS garnered 150 responses from administrator, classroom teachers and support teachers. The analysis of their responses showed "a direct relationship between the distributed leadership dimensions in the high performing and transition schools," (Gordon, 2005, p. 47). The second, larger sample was used and consisted of 36 Connecticut schools. The survey was completed by 1,931 administrators, classroom teachers and support teachers with a $68.8 \%$ response rate. The results of this data collection were used to conduct exploratory factor analysis to determine if the data was suitable the full factor analysis.

Construct validity. Factor analysis was used by Gordon (2005) to measure the relationship among items on the DLRS. This analysis allowed for the investigation of relationships among items on a survey. Additionally, construct validity was used to examine if the items were actually measuring the five dimensions of distributed leadership established by 
the authors. The results of the second data collection were used to conduct exploratory factor analysis to determine if the data could be used for full factor analysis. The full factor analysis is used to determine the categories of the items being used. The results of these initial tests supported Gordon's decision to continue with the five dimensions of distributed leadership.

Once the final analysis was completed, Gordon determined that the items in three dimensions: Mission, Vision, and Goal; School Culture, and Leadership Practices were measuring their intended purpose. The final two dimensions, Decision Making and Professional Development were combined into a single dimension, Shared Responsibility. To determine validity for the DLRS, the factor loadings were calculated for each item. Following a common social science practice, Gordon (2005) used .35 as the minimum cut off factor loading to determine validity. Due to all items loading above .35 , construct validity was established for the DLRS.

Reliability. Reliability was also established for the DLRS by Gordon (2005) for her study. Reliability is the degree of stability exhibited when a measurement is repeated under identical conditions. For her testing, Gordon (2005) used the internal consistency method. This method "was used to examine the correlation among all the items measuring each dimension contained on the instrument" (Christy, 2008, p. 70). For all items, Gordon (2005) used item-total correlation to show the correlation of particular items with the remaining items in the dimension. Gordon's results showed "the reliability coefficient for all the dimension was above the recommended .7 and the item-total correlations were all above the recommended .3 " (p. 58). Using these results, Gordon (2005) determined that the DLRS was a reliable instrument.

The DLRS to be used in this research has 4 dimensions. Table 2 shows the breakdown of DLRS number items by dimensions. 


\section{Table 2}

Items of the Distributed Leadership Readiness Scale Mapped, by Dimension (Gordon, 2005).

$\underline{\text { Dimension }}$

Mission, vision, and goals

School culture

Leadership practices

Shared responsibility

\section{$\underline{\text { Item Number }}$}

$1,2,3,4,5,6,7,8$

$13,14,15,16,23,24,26,27,28,29,30,32,33$

$25,31,34,35,36,37,38,39,40$

$9,10,11,12,17,18,19,20,21,22$

School-based committee influence survey. A supplemental survey was developed to gain the perceptions of the principals about the West Virginia statutes and policies which establish selected school-based committees. These committees were selected due to each having the potential to influence leadership in their schools. Research was completed to find an existing survey, but only one study related to the topic could be found; however, it lacked a survey suitable for this proposed research. The study was completed by Hallinger and Heck (2009b) and the study collected data from two hundred elementary schools over a three year period. This longitudinal study collected data from school background data, school outcome data and survey data about school processes. Their results pointed out that even with distributed leadership policies in place, the principal was still essential to the school improvement process. Without an existing instrument, a new instrument was developed to measure principals' perceptions.

The instrument uses the seven committees as found in West Virginia Statute and State Board Policy reviewed in the literature review. Each was reviewed for the specific areas of responsibilities, membership, and frequency of meetings. This information was then summarized into a statement about the statute or policy, as well as with a citation of where the code or policy can be found. Participants were asked to respond to each using a 4 point Likert 
scale, with the purpose of collecting principals' perceptions about the level of influence each group has on leadership in the school.

Validity and reliability. Validity and reliability were established for the School-Based Committee Influence Survey. A panel of experts was used to determine content validity of the survey. West Virginia education law experts were selected for participation on the panel. The members of the panel were Kathy Finsley, J.D, Howard Suefer, J.D, and Sherri Reveal, J.D. Ms. Finsley served as general counsel for Ohio County Schools for 20 years and worked in education for 33 years. She is currently an attorney for Steptoe \& Johnson, LLP where she specializes in labor, employment and education law. Mr. Suefer is an attorney for Bowles Rice LLP and has specialized in education law for the last 35 years. He has represented county boards of education, regional educational service agencies, and the West Virginia Department of Education. Currently, he is serving as legal counsel for the West Virginia School Board Association. Ms. Reveal is an education attorney currently employed by the West Virginia Department of Education in the Office of Legal Services.

Each member of the panel was sent an email explaining the process and a form to be used to review the items of the School-Based Committee Influence Survey for accuracy (See Appendix C). They were asked to compare the summary for each item with their corresponding laws and policies for correctness. The item could then be marked as "Accurate as is" or it could be corrected. The responses were collected from the panel of experts and the changes were made to the survey.

The review showed minor changes were needed for the items for faculty senate, professional staff development council, and local school improvement council. Two items needed revised to match the corresponding laws and policies correctly, as noted in feedback from 
one expert. Five-year strategic planning committees needed to be changed to school leadership team. This team is the committee that is granted authority to create the five-year strategic plan in West Virginia School Board Policy 2510. Teacher mentors was also revised to match West Virginia State Code $§ 18 A-3 C-3(j)(d)(5)$. Each of these two items were then resubmitted and were verified to be accurately summarizing their corresponding laws and policies.

Cronbach's Alpha was used to determine the reliability of the School-Based Committee Influence Survey post data collection. This measures the internal consistency of a survey to determine how closely the survey items are related. The relationship provides evidence that the items on the survey are measuring the same constructs. Cronbach's Alpha uses the correlations between items to determine a reliability coefficient. A Cronbach's Alpha value of .70 or higher is considered high internal consistency. The Cronbach's Alpha was .742 for this survey and determines it to be a reliable instrument.

Data collection. The population for this survey consisted of the 674 principals of West Virginia Schools. An initial email with an overview of the study was sent to county superintendents to inform them of the study with an attached letter, see Appendix D. All principal and superintendent contact information was collected from the West Virginia Department of Education.

The survey was administered online using the West Virginia University Qualtrics survey software. Utilizing an online survey tool allowed the study to be completed more efficiently, and it can help lead to a higher response rate (Fricker \& Schonlau, 2002). Principals were provided an introductory letter (see Appendix F) in a brief email, a link for the survey and an IRB approved statement assuring confidentiality and anonymity. The survey window was open for 
two weeks, which is an optimal window for a higher response rate (Gay, Mills, \& Airasian, 2002).

The initial superintendent email and the principal email were sent out on July 1, 2015. The survey was available to the participants upon receiving the initial email. A second email was sent out on day four, thanking those who responded and as a reminder for those who had not completed the survey. On day eight and day twelve a reminder email was sent out to those who had not responded. On the final day that the survey was open, one final email was sent out requesting participation in the study. Incentives were used to encourage responses from the principals. Those responding by the end of the fourth, eight, and twelfth day were able to enter into three separate, random drawings for a \$50 gift card from Amazon, Google Play, or ITunes.

\section{Data Analysis}

Mean scores and standard deviations were calculated for each of the items to determine distributed leadership readiness as well as principals' perceptions of the influence of the schoolbased committees on the leadership of the school. The DLRS has forty Likert scale items with a rating of Continually (4) to Rarely/Never (1) and an option of Insufficient Information was used and these items were coded as missing.

The School-Based Committee Influence Survey has seven items and were rated with Strong Influence (4) to No Influence (1) and an option of Insufficient Information was used and these items were coded as missing. For the School-Based Committee Influence Survey the higher the mean for each item, the greater amount of influence each school-based committee has on the leadership of the school.

The specific method of data analysis for each question was as follows:

Question 1: What is the distributed leadership readiness of West Virginia principals? 
Responses for all forty items were used to calculate the mean scores to describe the results and standard deviations to show the distribution of the responses. Means and standard deviations were also calculated by the four dimensions. The dimension means were calculated by using the means of the individual items. These mean scores show the level of distributed leadership readiness by item and dimension. The standard deviations for the items were used to determine any data outliers. These outliers were examined to determine if responses needed to be excluded from the statistical analysis.

Question 2: What are West Virginia principals’ perceptions of selected school-based committees which influence leadership in their schools?

Responses for all seven items were used to calculate the mean scores to describe the results and standard deviation to show the distribution of the responses. The mean scores for the items were used to show the perceived influence on school leadership for each of the schoolbased committees. The standard deviations for the items were used to determine any data outliers. These outliers were examined to determine if they should have been excluded from the statistical analysis.

Question 3: What is the relationship between the distributed leadership readiness of West Virginia principals and their perceptions of selected school-based committees which influence leadership in their schools?

The null Hypothesis for this question was:

$\mathrm{H}_{0}$ : There is not a relationship between the distributed leadership readiness of West Virginia principals and their perceptions of selected school-based committees which influence leadership in their schools.

The alternative hypothesis for this question was: 
$\mathrm{H}_{\mathrm{a}}$ : There is a relationship between the distributed leadership readiness of West Virginia principals and their perceptions of selected school-based committees which influence leadership in their schools.

Correlations were used to determine if the means of the DLRS dimensions had a relationship to each school-based committee from the School-Based Committee Survey. This analysis allowed for an examination of the linear relationship of the two variables and provided a strength of association between the variables. A p-value of $\mathrm{p} \leq .05$ was used to determine statistically significant findings. Statistically significant correlation results showed if there was a relationship between the DLRS dimensions and specific school-based committees.

Question 4: Is there a difference between specific demographic characteristics of principals and their distributed leadership readiness?

The null Hypothesis for this question and gender was:

$\mathrm{H}_{0}$ : There is not a significant difference between gender and the distributed leadership readiness of West Virginia principals.

The alternative hypothesis for this question and gender was:

$\mathrm{H}_{\mathrm{a}}$ : There is a significant difference between gender and the distributed leadership readiness of West Virginia principals.

The null Hypothesis for this question and years of experience in education was: $\mathrm{H}_{0}$ : There is not a significant difference between years of experience in education and the distributed leadership readiness of West Virginia principals.

The alternative hypothesis for this question and years of experience in education was: $\mathrm{H}_{\mathrm{a}}$ : There is a significant difference between years of experience in education and the distributed leadership readiness of West Virginia principals. 
The null Hypothesis for this question and years of experience in the school was:

$\mathrm{H}_{0}$ : There is not a significant difference between years of experience in the school and the distributed leadership readiness of West Virginia principals.

The alternative hypothesis for this question and years of experience in the school was: $\mathrm{H}_{\mathrm{a}}$ : There is a significant difference between years of experience in the school and the distributed leadership readiness of West Virginia principals.

The null Hypothesis for this question and programmatic level was:

$\mathrm{H}_{0}$ : There is not a significant difference between programmatic level and the distributed leadership readiness of West Virginia principals.

The alternative hypothesis for this question and programmatic level was:

$\mathrm{H}_{\mathrm{a}}$ : There is a significant difference between programmatic level and the distributed leadership readiness of West Virginia principals.

After the survey was closed, the responses were collected and examined. During the examination, it was found that large differences existed between the number of respondents for the demographic groups. These large differences made correlations an ineffective test to use to answer the proposed research question. Correlation analysis requires paired data sets for comparison. Since these large differences existed for the respondent groups the only way to have used correlations would have been to eliminate responses to create equal groups. The decision was made to change Research Question 4 from a relationship question to a significant difference question. This also changed the data analysis method to an ANOVA.

A One-Way Analysis of Variance (ANOVA) was used to determine if there were any significant differences and to test the hypotheses for this research question. An ANOVA tests for significant differences between multiple group means. When a significant difference was 
found, the ANOVA results signified that a difference exists. When more than two groups were compared, the ANOVA results did specify the groups with the significant difference. A post hoc test was then run to determine the groups with significant differences. A p-value of $p \leq .05$ was used to determine statistically significant findings. Statistically significant results showed if there was a significant difference between the DLRS dimensions and specific demographic factors.

\section{Summary}

The purpose of this study was to answer the following research questions: 1) What is the distributed leadership readiness of West Virginia principals? 2) What are West Virginia principals' perceptions of selected school-based committees which influence leadership in their schools? 3) What is the relationship between the distributed leadership readiness of West Virginia principals and their perceptions of selected school-based committees which influence leadership in their schools? 4) Is there a difference between specific demographic characteristics of principals and their distributed leadership readiness?

West Virginia principals were surveyed for this study using the Distributed Leadership Readiness Scale (see Appendix A) and the School-Based Committee Influence Survey (see Appendix B). The DLRS was used to measure the distributed leadership readiness of the principal. Gordon (2005) tested the DLRS and found it to be valid and reliable. The second survey was developed based on West Virginia statutes and laws which establish specific schoolbased committees which can influence the leadership of the school. The survey was examined by a panel of experts for content validity and after some minor changes, determined to be valid. After the survey closed, the results from the respondents were used to test for internal 
consistency with Cronbach's Alpha and determined it to be a reliable survey. This survey was used to collect the perceptions of principals for these specific statutes and laws. 


\section{Chapter 4}

\section{Results}

The purpose of this study was to determine the relationship between the distributed leadership readiness of West Virginia principals and their perceptions of selected school-based committees which influence leadership in their schools. Invitations were sent to all West Virginia principals to participate in the study by completing the online survey.

Chapter 4 provides a description and analysis of the data collected using the Distributed Leadership Readiness Scale (DLRS) and School-Based Committee Influence Survey. This chapter includes the return rate, demographics, data addressing the four research questions and a summary of the findings.

\section{Return Rate}

The population for this study was the principals of the 674 schools in West Virginia. Of this group, 210 principals started the survey and 198 submitted a completed survey, for a return rate of 29.3\%. According to Survey Monkey (2011), the online survey average response rate is $30 \%$ and that average goes up to $40 \%$ if the survey is distributed by email. This survey fell short of the $30 \%$ average, although the response rate was higher than expected due to the time of year it was administered.

In a study without a large return rate, the data can still be generalized if the characteristics of the early and late respondents are similar (Miller \& Smith, 1983). To compare the early and late respondents, the first 40 respondents' demographic factors were compared to the demographic factors of the last 40 respondents. This comparison can be seen in Table 3, which shows the demographic factors, categories, early responses, late responses, and the difference. 


\section{Table 3}

Comparison of Demographic Factors of Early and Late Respondents

\begin{tabular}{lccc}
\hline & Early & Late & \\
Demographic & $(\mathrm{n}=40)$ & $(\mathrm{n}=40)$ & Difference \\
\hline
\end{tabular}

Gender

Female

Male

Years Experience in Education

$7+$

4-6

2-3

1 or less

Years Experience in School

$7+$

4-6

2-3

1 or less

Programmatic Level

Early Learning (PreK-5)

Middle (5-8)

Adolescent (9-12)
23

17

40

0

0

0
24

16
0

0

0

0

$\begin{array}{ll}0 & 0 \\ 0 & 0\end{array}$




\section{Demographics}

The DLRS, found in Appendix A, collected demographic data from the principals.

Demographic questions were asked about gender, years of experience in education, years of experience in their school, and programmatic level. The data can be found in Table 4 which shows the number and percent of respondents in each demographic.

\section{Table 4}

Demographics of Respondents

\begin{tabular}{lc}
\hline \multicolumn{1}{c}{ Demographic } & No. (\%) of Respondents \\
\hline Gender & \\
Female & $124(63 \%)$ \\
Male & $74(37 \%)$ \\
Years Experience in Education & \\
$7+$ & $196(99 \%)$ \\
$4-6$ & $2(1 \%)$ \\
& \\
Years Experience in School & \\
$7+$ & $97(49 \%)$ \\
$4-6$ & $46(23 \%)$ \\
$2-3$ & $51(26 \%)$ \\
1 or less & $4(2 \%)$ \\
Programmatic Level & \\
Early Learning (PreK-5) & $119(60 \%)$ \\
Middle Level (5-8) & $35(18 \%)$ \\
Adolescent Level (9-12) & $44(22 \%)$ \\
\end{tabular}

The number of principals responding that were female was $124(63 \%)$ and the males were $74(37 \%)$. For the principals who responded 196 of 198 (99\%) have been in education for 7 or more years. Nearly one-half of the principals, 97 (49\%) have been in their school for 7 or more years, $46(23 \%)$ were in their school for 4 to 6 years, $51(26 \%)$ were in their school for 2 to 3 years and only $4(2 \%)$ were in their school for 1 year or less. The last demographic factor in 
Table 4 is the programmatic level of the principals' school. Early learning had the most principal respondents with 119 (60\%), then adolescent level had 44(22\%) principals and middle level had 35 (18\%) principals.

\section{Research Question 1}

What is the distributed leadership readiness of West Virginia principals? The mean and standard deviation were calculated for each item on the DLRS, found in Appendix A. The Likert scale anchors used for this survey were Continually (4), Frequently (3), Sometimes (2), and Rarely/Never (1). A total mean was calculated using the means of all the items from the DLRS to establish high and low mean groups. This method was used because prior research using the DLRS did not establish these means. The total mean for this for the DLRS was 3.38. Any item with a mean higher than the total mean was considered a high mean and any mean which was lower was considered a low mean. A high mean shows a higher readiness for distributed leadership. The standard deviations show the dispersion of the responses for each item on the survey. The smaller the standard deviation, the closer the responses were to the mean. For all the items, the individual standard deviations were less than 0.97 . This shows that the responses were all relatively close to the mean value of the items and no responses had to be eliminated as outliers. Table 5 shows the items, means and standard deviations for each item of the DLRS. The items are listed by their mean score in descending order. 


\section{Table 5}

Distributed Leadership Readiness Scale Items Means and Standard Deviations

\begin{tabular}{|c|c|c|c|}
\hline \multicolumn{2}{|r|}{ DLRS Item } & \multirow{2}{*}{ Mean } & \multirow{2}{*}{$\begin{array}{c}\begin{array}{c}\text { Standard } \\
\text { Deviation }\end{array} \\
0.37\end{array}$} \\
\hline 8 & $\begin{array}{l}\text { The school's curriculum is aligned with the state's academic } \\
\text { standards. }\end{array}$ & & \\
\hline 15 & $\begin{array}{l}\text { The school administrator(s) welcome professional staff members input } \\
\text { on issues related to curriculum, instruction, and improving student } \\
\text { performance. }\end{array}$ & 3.80 & 0.45 \\
\hline 23 & $\begin{array}{l}\text { The principal actively encourages teachers and other staff members to } \\
\text { participate in instructional decision-making. }\end{array}$ & 3.76 & 0.45 \\
\hline 9 & $\begin{array}{l}\text { Teachers and administrators have high expectations for students' } \\
\text { academic performance. }\end{array}$ & 3.75 & 0.47 \\
\hline 1 & The school has clearly written vision and mission statements. & 3.74 & 0.53 \\
\hline 7 & $\begin{array}{l}\text { Teachers and administrators collectively establish school goals and } \\
\text { revise goals annually. }\end{array}$ & 3.74 & 0.53 \\
\hline 27 & $\begin{array}{l}\text { The principal actively participates in his/her own professional } \\
\text { development activities to improve leadership in the school. }\end{array}$ & 3.73 & 0.51 \\
\hline 20 & $\begin{array}{l}\text { The school makes available a variety of data (e.g. student } \\
\text { performance) for teachers to use to improve student achievement. }\end{array}$ & 3.71 & 0.49 \\
\hline 5 & School goals are aligned with its mission statement. & 3.69 & 0.51 \\
\hline 33 & The principal's practices are consistent with his/her words. & 3.69 & 0.47 \\
\hline 10 & $\begin{array}{l}\text { Teachers and administrators share accountability for students' } \\
\text { academic performance. }\end{array}$ & 3.67 & 0.54 \\
\hline 32 & The principal is knowledgeable about current instructional issues. & 3.66 & 0.53 \\
\hline 16 & The school supports using new instructional ideas and innovations. & 3.61 & 0.55 \\
\hline 24 & $\begin{array}{l}\text { Professional staff members in the school have the responsibility to } \\
\text { make decisions that affect meeting school goals. }\end{array}$ & 3.61 & 0.55 \\
\hline 26 & $\begin{array}{l}\text { Administrators participate alongside teachers in the school's } \\
\text { professional development activities. }\end{array}$ & 3.60 & 0.59 \\
\hline 30 & Teachers actively participate in instructional decision-making. & 3.58 & 0.53 \\
\hline 14 & $\begin{array}{l}\text { There is mutual respect and trust between the school administration } \\
\text { and the professional staff. }\end{array}$ & 3.55 & 0.54 \\
\hline 22 & $\begin{array}{l}\text { There is a formal structure in place in the school (e.g. curriculum } \\
\text { committee) to provide teachers and professional staff opportunities to } \\
\text { participate in school-level instructional decision-making. }\end{array}$ & 3.55 & 0.61 \\
\hline & $\begin{array}{l}\text { The school is a learning community that continually improves its } \\
\text { effectiveness, learning from both successes and failures. }\end{array}$ & 3.51 & 0.60 \\
\hline 2 & $\begin{array}{l}\text { Teachers and administrators understand and support a common } \\
\text { mission for the school and can describe it clearly. }\end{array}$ & 3.45 & 0.62 \\
\hline 6 & $\begin{array}{l}\text { The school uses a school improvement plan as a basis to evaluate the } \\
\text { progress it is making in attaining its goals. }\end{array}$ & 3.45 & 0.73 \\
\hline
\end{tabular}


13 There is a high level of mutual respect and trust among the teachers and other professional staff in the school.

34 Informal school leaders play an important role in the school in improving the performance of professionals and the achievement of students.

29 My professional development plan includes activities that are based on my individual professional needs and school needs.

$3.43 \quad 0.60$

$3.41 \quad 0.64$

$3.41 \quad 0.76$

21. Decisions to change curriculum and instructional programs are based $\quad 3.40 \quad 0.66$ on assessment data.

25 The school provides teachers with professional development aligned $\quad 3.37 \quad 0.69$ with the school's mission and goals.

19 The school clearly communicates the 'chain of contact' between home $\quad 3.35 \quad 0.61$ and school so parents know who to contact when they have questions and concerns.

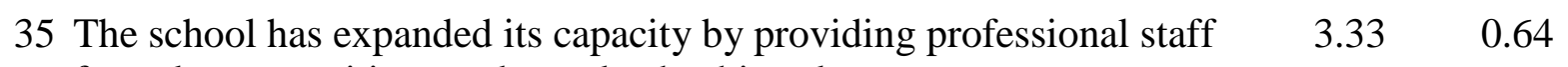
formal opportunities to take on leadership roles.

17 The school's daily and weekly schedules provide time for teachers to $\quad \begin{array}{lll}3.32 & 0.87\end{array}$ collaborate on instructional issues.

11 School and district resources are directed to those areas in which $\quad 3.24 \quad 0.72$ student learning needs to improve most.

37 Teachers who assume leadership roles in the school have sufficient resources to be able to make meaningful contributions to the school.

28 My supervisor and I jointly develop my annual professional $\quad 3.08 \quad 0.97$ development plan.

36 Teachers who assume leadership roles in the school have sufficient school time to permit them to make meaningful contributions to the school.

39 New teachers are provided opportunities to fill some school leadership roles.

40 Teachers are interested in participating in school leadership roles. $\quad \begin{array}{lll}2.89 & 0.74\end{array}$

18 School professionals and parents agree on the most effective roles $\quad 2.88 \quad 0.71$ parents can play as partners in their child's education.

$\begin{array}{llll}31 \text { Central office and school administrators work together to determine } & 2.80 & 0.85\end{array}$ the professional development activities.

38 Veteran teachers fill most leadership roles in the school. $\quad 2.61 \quad 0.76$

4 If students are asked to describe the school's mission, most would be $\quad 2.57 \quad 0.88$ able to describe the mission generally.

$\begin{array}{llll}3 & \text { If parents are asked to describe the school's mission, most would be } & 2.32 & 0.81\end{array}$ able to describe the mission clearly.

Twenty-five of 40 items were above the 3.38 overall mean and are considered high means. Their individual mean values ranged from 3.87 to 3.40 . 
Six items had the highest means. Item 8 with a mean of 3.87 , states "The school's curriculum is aligned with the state's academic standards." Item 15 with a mean of 3.80 , states "The school administrator(s) welcome professional staff members input on issues related to curriculum, instruction, and improving student performance." Item 23, with a mean of 3.76, states "The principal actively encourages teachers and other staff members to participate in instructional decision-making." Item 9, with a mean of 3.75, states "Teachers and administrators have high expectations for students' academic performance." Lastly, two items had a mean of 3.74. Item 1 states, "The school has clearly written vision and mission statements" and item 7 states, "Teachers and administrators collectively establish school goals and revise goals annually."

Nineteen more items were in the high mean group. Item 27, with a mean of 3.73, states "The principal actively participates in his/her own professional development activities to improve leadership in the school." Item 20, with a mean of 3.71, states "The school makes available a variety of data (e.g. student performance) for teachers to use to improve student achievement." Item 5, with a mean of 3.69, states "School goals are aligned with its mission statement." Item 33, with a mean of 3.69, states "The principal's practices are consistent with his/her words." Item 10, with a mean of 3.67, states "Teachers and administrators share accountability for students' academic performance." Item 32, with a mean of 3.66, states "The principal is knowledgeable about current instructional issues." Item 16, with a mean of 3.61, states "The school supports using new instructional ideas and innovations." Item 24, with a mean of 3.61, states "Professional staff members in the school have the responsibility to make decisions that affect meeting school goals." Item 26, with a mean of 3.60, states "Administrators participate alongside teachers in the school's professional development activities." 
Item 30 , with a mean of 3.58 , states "Teachers actively participate in instructional decision-making." Item 14, with a mean of 3.55, states "There is mutual respect and trust between the school administration and the professional staff." Item 22, with a mean of 3.55, states "There is a formal structure in place in the school (e.g. curriculum committee) to provide teachers and professional staff opportunities to participate in school-level instructional decisionmaking." Item 12, with a mean of 3.51 , states "The school is a learning community that continually improves its effectiveness, learning from both successes and failures." Item 2, with a mean of 3.45, states "Teachers and administrators understand and support a common mission for the school and can describe it clearly." Item 6, with a mean of 3.45, states "The school uses a school improvement plan as a basis to evaluate the progress it is making in attaining its goals." Item 13, with a mean of 3.43 , states "There is a high level of mutual respect and trust among the teachers and other professional staff in the school." Item 34, with a mean of 3.41, states "Informal school leaders play an important role in the school in improving the performance of professionals and the achievement of students." Item 29, with a mean of 3.41, states "My professional development plan includes activities that are based on my individual professional needs and school needs." Item 21, with a mean of 3.40, states "Decisions to change curriculum and instructional programs are based on assessment data.

Eleven items fell below the 3.38 overall mean value and are considered low means. Their means ranged from 2.32 to 3.37. There were five items with the lowest means. Item 3, with a mean of 2.32, states "If parents are asked to describe the school's mission, most would be able to describe the mission clearly." Item 4 , with a mean of 2.57 , states "If students are asked to describe the school's mission, most would be able to describe the mission generally." Item 38, with a mean of 2.61, states "Veteran teachers fill most leadership roles in the school." Item 31, 
with a mean of 2.80 , states "Central office and school administrators work together to determine the professional development activities." Lastly, item 18, with a mean of 2.88 , states "School professionals and parents agree on the most effective roles parents can play as partners in their child's education."

Also included in the analysis for Research Question 1, were the means and standard deviations of the 4 dimensions of the DLRS. The means for each item in the dimension were used to calculate the mean for each dimension. The total mean for this for the DLRS, 3.38, was used to group the dimension means. This was done to be able to create mean groups and because the prior research did not establish high or low means. Any item with a mean higher than the total mean would be considered a high mean and any mean which was lower would be considered a low mean. A high mean shows a higher readiness for distributed leadership within the dimension. The standard deviations show the dispersion of the responses for all items within the dimension. The smaller the standard deviation, the closer the responses were to the mean. For all the items, the individual standard deviations were less than 0.63 and show low dispersion of responses. Table 6 shows the DLRS dimension, items included in the dimension, the dimension mean, and the standard deviation. 


\section{Table 6}

Distributed Leadership Readiness Scale Dimensions, Mean with Item Numbers

\begin{tabular}{lcc}
\multicolumn{1}{c}{ DLRS Dimension (Item Numbers) } & Mean & $\begin{array}{c}\text { Standard } \\
\text { Deviation }\end{array}$ \\
\hline $\begin{array}{l}\text { School Culture } \\
(13,14,15,16,23,24,26,27,28,29,30,32,33)\end{array}$ & 3.56 & 0.26 \\
$\begin{array}{l}\text { Shared Responsibility } \\
(9,10,11,12,17,18,19,20,21,22)\end{array}$ & 3.44 & 0.25 \\
$\begin{array}{l}\text { Mission, Vision, and Goals } \\
(1,2,3,4,5,6,7,8)\end{array}$ & 3.35 & 0.55 \\
Leadership Practices \\
$(25,31,34,35,36,37,38,39,40)$
\end{tabular}

Two dimensions were above the 3.38 overall mean value and are considered high means. School culture had the highest mean of 3.56 and included 13 items. Shared Responsibility had the second highest mean of 3.44 and included 10 items. Two dimensions were below the 3.38 overall mean value and are considered low means. Leadership Practices had the lowest mean of 3.01 and included 9 items. Mission, Vision, and Goals had the second lowest mean of 3.35 and included 8 items

\section{Research Question 2}

What are West Virginia principals' perceptions of selected school-based committees which influence leadership in their schools? The mean and standard deviation were calculated for each item of the School-Based Committee Influence Survey (Appendix B). The Likert scale anchors used for this survey were Strong Influence (4), Moderate Influence (3), Slight Influence (2), and No Influence (1). A total mean was calculated using the means for all items to establish high and low mean groups. This method was used because the School-Based Committee Influence Survey was a new instrument and had not been used in any prior research. The total 
mean for this survey was 3.16. A high mean shows a higher perceived influence on leadership, while the lower means show less of a perceived influence on leadership. For each item, all of the standard deviations were less than 0.82 . This shows that the responses were all relatively close to the total mean value and no responses had to be eliminated as outliers. Table 7 below shows the items with their means and the standard deviations. The items are listed by their mean score in descending order.

\section{Table 7}

School-Based Committee Influence Survey Means and Standard Deviations

\begin{tabular}{lcc}
\hline \multicolumn{1}{c}{ Statute/Policy } & Mean & Standard Deviation \\
\hline School Leadership Team & 3.43 & 0.67 \\
School Curriculum Team & 3.42 & 0.68 \\
Faculty Senates & 3.41 & 0.64 \\
Mentors, Master Teachers, and Academic Coaches & 3.02 & 0.76 \\
School Technology Team & 2.96 & 0.82 \\
Local School Improvement Council & 2.95 & 0.75 \\
Professional Development Council & 2.89 & 0.80 \\
\hline
\end{tabular}

Three of the school-based committees were above the 3.16 total mean value and are considered to be high means. School Leadership Team (3.43), School Curriculum Teams (3.42), and Faculty Senates (3.41) all had means above the total mean value. Principal respondents perceived that these three school-based committees have a high perceived influence on the leadership of the school. Four committees fell below the total mean value and are considered to have low means. Professional Development Council (2.89), Local School Improvement Council 
(2.95), School Technology Team (2.96) and Mentors, Master Teachers and Academic Coaches (3.02) all had values below the total mean value.

\section{Research Question 3}

What is the relationship between the distributed leadership readiness of West Virginia principals and their perceptions of selected school-based committees which influence leadership in their schools?

The null Hypothesis for this question was:

$H_{0}$ : There is not a relationship between the distributed leadership readiness of West Virginia principals and their perceptions of selected school-based committees which influence leadership in their schools.

The alternative hypothesis for this question was:

$H_{a}$ : There is a relationship between the distributed leadership readiness of West Virginia principals and their perceptions of selected school-based committees which influence leadership in their schools.

Correlations were used to measure the relationship between the means for the DLRS dimensions and the means of the School-Based Committee Influence survey items. A Pearson $r$ correlation was run using SPSS statistics software Version 21.0. This test used the two sets of means to determine if there was a statistical relationship between them. A correlation shows the strength of the relationship between a set of paired means. The relationship can be from +1.00 , a perfect positive relationship, to a -1.00 , a perfect negative relationship. The positive relationship rankings are very strong $(+.70$ or higher), strong $(+.69$ to +.40$)$, moderate $(+.39$ to +.30$)$, weak $(+.29$ to +.20$)$, and none or negligible $(+.19$ to .01$)$. The negative relationship rankings are very strong (-.70 or higher), strong (-.69 to -.40$)$, moderate (-.39 to -.30$)$, weak (-.29 to -.20$)$, and none 
or negligible (-.19 to -.01). A two-tailed test was used to test for significance. This tests the correlations in both directions, positive and negative, for significance. A $p \leq .05$ was used to determine statistically significant findings. Table 8 shows the correlation results between the DLRS dimensions and the School-Based Committee Influence survey items and the significance. 


\section{Table 8}

Correlations of School-Based Committees and DLRS Dimensions $(N=198)$

\begin{tabular}{|c|c|c|c|c|c|}
\hline \multirow[t]{2}{*}{ Committees } & \multicolumn{5}{|c|}{ Dimensions } \\
\hline & & $\begin{array}{l}\text { Mission, } \\
\text { Vision and } \\
\text { Goals } \\
\end{array}$ & $\begin{array}{l}\text { School } \\
\text { Culture }\end{array}$ & $\begin{array}{l}\text { Leadership } \\
\text { Practices }\end{array}$ & $\begin{array}{c}\text { Shared } \\
\text { Responsibility }\end{array}$ \\
\hline Faculty Senates & $\begin{array}{l}\text { Pearson } r \\
\text { Sig.(2- } \\
\text { tailed) }\end{array}$ & $\begin{array}{l}.308^{* *} \\
.000\end{array}$ & $\begin{array}{l}.234^{* *} \\
.001\end{array}$ & $\begin{array}{l}.219^{* *} \\
.002\end{array}$ & $\begin{array}{l}.264^{* * *} \\
.000\end{array}$ \\
\hline $\begin{array}{l}\text { Professional } \\
\text { Development } \\
\text { Council }\end{array}$ & $\begin{array}{l}\text { Pearson } r \\
\text { Sig.(2- } \\
\text { tailed) }\end{array}$ & $\begin{array}{l}.263^{* *} \\
.000\end{array}$ & $\begin{array}{l}.266^{* *} \\
.000\end{array}$ & $\begin{array}{l}.269^{* *} \\
.000\end{array}$ & $\begin{array}{l}.239^{* *} \\
.001\end{array}$ \\
\hline $\begin{array}{c}\text { School } \\
\text { Curriculum }\end{array}$ & Pearson $r$ & $.414^{* *}$ & $.414^{* *}$ & $.487^{* *}$ & $.461^{* *}$ \\
\hline Team & $\begin{array}{l}\text { Sig.(2- } \\
\text { tailed) }\end{array}$ & .000 & .000 & .000 & .000 \\
\hline $\begin{array}{l}\text { Local School } \\
\text { Improvement } \\
\text { Council }\end{array}$ & $\begin{array}{l}\text { Pearson } r \\
\text { Sig.(2- } \\
\text { tailed) }\end{array}$ & $\begin{array}{l}.340^{* *} \\
.000\end{array}$ & $\begin{array}{l}.241^{* *} \\
.001\end{array}$ & $\begin{array}{l}.306^{* *} \\
.000\end{array}$ & $\begin{array}{l}.365^{* *} \\
.000\end{array}$ \\
\hline $\begin{array}{c}\text { School } \\
\text { Leadership }\end{array}$ & Pearson $r$ & $.224^{* *}$ & $.292^{* *}$ & $.368^{* *}$ & $.324^{* * *}$ \\
\hline Team & $\begin{array}{l}\text { Sig.(2- } \\
\text { tailed) }\end{array}$ & .001 & .000 & .000 & .000 \\
\hline $\begin{array}{c}\text { Mentors, Master } \\
\text { Teachers, and } \\
\text { Academic } \\
\text { Coaches }\end{array}$ & $\begin{array}{l}\text { Pearson } r \\
\text { Sig.(2- } \\
\text { tailed) }\end{array}$ & $\begin{array}{l}.276^{* *} \\
.000\end{array}$ & $\begin{array}{l}.275^{* *} \\
.000\end{array}$ & $\begin{array}{l}.356^{* *} \\
.000\end{array}$ & $\begin{array}{l}.363^{* *} \\
.000\end{array}$ \\
\hline $\begin{array}{c}\text { School } \\
\text { Technology Team }\end{array}$ & $\begin{array}{l}\text { Pearson } r \\
\text { Sig.(2- } \\
\text { tailed) }\end{array}$ & $\begin{array}{l}.364^{* *} \\
.000\end{array}$ & $\begin{array}{l}.366^{* *} \\
.000\end{array}$ & $\begin{array}{l}.374^{* *} \\
.000\end{array}$ & $\begin{array}{l}.407^{* *} \\
.000\end{array}$ \\
\hline
\end{tabular}

**Correlation is significant at the 0.01 level (2-tailed)

All of the 28 relationships' significance levels were below the p-value of .01 and are statistically significant. There were 5 strong positive relationships, 11 moderate positive 
relationships, and 12 weak positive relationships. The five strong positive relationships ranged from .407 to .487 . The School Curriculum Team had a strong positive relationship with all four of the DLRS dimensions: Leadership Practices $(r=.487, \mathrm{p}=.000)$, Shared Responsibility $(\mathrm{r}=.461$, $\mathrm{p}=.000)$, Mission, Vision, and Goals $(\mathrm{r}=.414, \mathrm{p}=.000)$ and School Culture $(\mathrm{r}=.414, \mathrm{p}=.000)$. School Technology Teams had a strong positive relationship with the DLRS dimension of Shared Responsibility $(\mathrm{r}=.407, \mathrm{p}=.000)$. Each school-based committee is next presented in order of the strength of its correlation with the DLRS dimension.

Curriculum Teams had four strong positive relationships with the dimensions from the DLRS. The strong positive relationships were with the dimensions of Mission, Vision, and Goals $(\mathrm{r}=.414, \mathrm{p}=.000)$, School Culture $(\mathrm{r}=.414, \mathrm{p}=.000)$, Leadership Practices $(\mathrm{r}=.487, \mathrm{p}=.000)$, and Shared Responsibility $(\mathrm{r}=.461, \mathrm{p}=.000)$. All of the relationships were statistically significant by being below the p-value of 0.05 used for this study.

School Technology Teams had one strong positive relationship and three moderate positive relationships with the dimensions from the DLRS. The moderate positive relationship was with Shared Responsibility $(r=.407, \mathrm{p}=.000)$. The three moderate relationships were with the dimensions of Mission, Vision, and Goals ( $r=.364, \mathrm{p}=.000)$, School Culture $(\mathrm{r}=.366, \mathrm{p}=.000)$, and Leadership Practices $(\mathrm{r}=.374, \mathrm{p}=.000)$. All of the relationships were statistically significant by being below the p-value of 0.05 which was used for this study.

Local School Improvement Councils had three moderate positive relationships and one weak positive relationship with the dimensions from the DLRS. The moderate positive relationships were with the dimensions of Mission, Vision, and Goals ( $r=.340, p=.000)$, Leadership Practices ( $\mathrm{r}=.306, \mathrm{p}=.000)$, and Shared Responsibility $(\mathrm{r}=.365, \mathrm{p}=.000)$. The weak 
relationship was with the dimension of School Culture $(r=.241, p=.001)$. All of the relationships were statistically significant by being below the p-value of 0.05 used for this study.

School Leadership Teams had two moderate positive relationships and two weak positive relationships with the dimensions from the DLRS. The moderate positive relationships were with the dimensions of Leadership Practices ( $\mathrm{r}=.368, \mathrm{p}=.000)$, and Shared Responsibility $(\mathrm{r}=.324, \mathrm{p}=.000$.) The weak relationships were with the dimensions of Mission, Vision, and Goals $(\mathrm{r}=.224, \mathrm{p}=.001)$ and School Culture $(\mathrm{r}=.292, \mathrm{p}=.000)$. All of the relationships were statistically significant by being below the p-value of 0.05 which was used for this study.

Mentors, Master Teachers, and Academic Coaches had two moderate positive relationships and two weak positive relationships with the dimensions from the DLRS. The moderate positive relationships were with the dimensions of Leadership Practices $(\mathrm{r}=.356$, $\mathrm{p}=.000)$, and Shared Responsibility ( $\mathrm{r}=.363, \mathrm{p}=.000$.) The weak relationships were with the dimensions of Mission, Vision, and Goals $(\mathrm{r}=.276, \mathrm{p}=.000)$ and School Culture $(\mathrm{r}=.275, \mathrm{p}=.000)$. All of the relationships were statistically significant by being below the p-value of 0.05 which was used for this study.

Faculty Senates had one moderate positive relationship and three weak positive relationships with the dimensions from the DLRS. The moderate positive relationship was with the dimension of Mission, Vision, and Goals ( $\mathrm{r}=.308, \mathrm{p}=.000)$. There were three weak relationships with the dimensions of School Culture $(r=.234, \mathrm{p}=.001)$, Leadership Practices $(\mathrm{r}=.219, \mathrm{p}=.002)$, and Shared Responsibility $(\mathrm{r}=.264, \mathrm{p}=.000)$. All of the relationships were statistically significant by being below the p-value of 0.05 used for this study.

Professional Development Councils had four weak positive relationship with the dimensions from the DLRS. The weak positive relationships were with the dimension of 
Mission, Vision, and Goals ( $r=.263$, $\mathrm{p}=.000)$, School Culture $(\mathrm{r}=.266, \mathrm{p}=.000)$, Leadership Practices $(\mathrm{r}=.269, \mathrm{p}=.000)$, and Shared Responsibility $(\mathrm{r}=.239, \mathrm{p}=.001)$. All of the relationships were statistically significant with a significance level below the p-value of 0.05 used for this study.

Overall, there were 5 strong positive relationships, 11 moderate positive relationships, and 12 weak positive relationships. All of the 28 relationships' significance levels were below the p-value of .05 and are statistically significant. The Pearson $r$ results allow the null hypothesis to be rejected and allow the alternative hypothesis to be accepted. The findings show that there is a relationship between the distributed leadership readiness of West Virginia principal respondents and their perceptions of selected school-based committees which influence leadership in their schools.

\section{Research Question 4}

Is there a difference between specific demographic characteristics of principals and their distributed leadership readiness? The means scores and standard deviations from the DLRS dimensions were used to determine if there were any significant differences between dimensions and the demographic factors. The demographic factors used in this analysis were gender, years of experience in education, years of experience in the school and programmatic level. A OneWay Analysis of Variance (ANOVA) was used to determine if there were any significant differences and to test the hypotheses for this research question. An ANOVA test for significant differences between multiple group means. A $p \leq .05$ was used to determine statistically significant findings. When a significant difference is found, the ANOVA results signify that a difference exists. When more than two groups were compared, the ANOVA results do specify 
the groups with the significant difference. A post hoc test was then run to determine the groups with significant differences.

For each demographic factor, the null hypothesis, the alternative hypothesis and the ANOVA table are presented. The table shows the significance by dimension, along with sum of squares, degrees of freedom (df), and the F statistic (F). The sum of squares shows the variance between groups; df shows the number of mean groups minus 1; and the F statistic is the ratio of the mean square values. All three of these are used in the calculations to determine the significance level between the groups being used. The larger the value of the F statistic indicates a better chance of significance.

The null hypothesis for this question and gender was:

$\mathrm{H}_{0}$ : There is not a significant difference between gender and the distributed leadership readiness of West Virginia principals.

The alternative hypothesis for this question and gender was:

$\mathrm{H}_{\mathrm{a}}$ : There is a significant difference between gender and the distributed leadership readiness of West Virginia principals.

Table 9 presents the ANOVA findings for the demographic factor of gender.

\section{Table 9}

ANOVA Results for Gender and DLRS Dimensions

\begin{tabular}{lcccc}
\hline \multicolumn{1}{c}{ Dimension } & Sum of Squares & df & F & Significance* \\
\hline Mission, Vision and Goals & .097 & 1 & .539 & .464 \\
School Culture & .885 & 1 & 7.893 & $.005^{*}$ \\
Shared Responsibility & .727 & 1 & 5.160 & $.024 *$ \\
Leadership Practices & .053 & 1 & .266 & .607 \\
$* p \leq .05$ & & & &
\end{tabular}


Female principal respondents showed a significant difference with the male principal respondents in their distributed leadership readiness for the DLRS dimensions of Shared Responsibility and School Culture. The ANOVA results for gender show two dimensions with significant differences at the $\mathrm{p} \leq .05$ level. School Culture had a significance value of $\mathrm{p}=.005$ and Shared Responsibility had a significance value of $p=.024$. These values show a significant difference between the female and male principals responding to the survey for these two dimensions. The means for these groups by dimension can be found in Appendix G. The table contains the means for each of the demographic factors by the DLRS dimensions.

For the dimension of School Culture, the females $(n=124)$ had a mean of 3.63 and the males $(n=74)$ had a mean of 3.49. For the dimension of Shared Responsibility, the females $(n=124)$ had a mean of 3.48 and the males $(n=74)$ had a mean of 3.36 .

The ANOVA results allow the null hypothesis to be rejected and allow the alternative hypothesis to be accepted. The findings show that there are significant differences between the distributed leadership readiness of West Virginia principal respondents and gender on two dimensions.

The null Hypothesis for this question and years of experience in education was: $\mathrm{H}_{0}$ : There is not a significant relationship between years of experience in education and the distributed leadership readiness of West Virginia principals.

The alternative hypothesis for this question and years of experience in education was:

$\mathrm{H}_{\mathrm{a}}$ : There is a significant relationship between years of experience in education and the distributed leadership readiness of West Virginia principals.

No statistical tests could be completed on the survey data to reject or accept the hypotheses for the demographic factor of the principals' years of experience in education since 
196 out of 198 had 7 or more years of experience in education. With this many respondents in one group the testing for significant differences could not be complete.

The null Hypothesis for this question and years of experience in the school was:

$\mathrm{H}_{0}$ : There is not a significant relationship between years of experience in the school and the distributed leadership readiness of West Virginia principals.

The alternative hypothesis for this question and years of experience in the school was:

$\mathrm{H}_{\mathrm{a}}$ : There is a significant relationship between years of experience in the school and the distributed leadership readiness of West Virginia principals.

Table 10 presents the ANOVA findings for the demographic factor of principals' years of experience in their school.

\section{Table 10}

ANOVA Results for Years of Experience in Their School and DLRS Dimensions

\begin{tabular}{lcccc}
\hline \multicolumn{1}{c}{ Dimension } & Sum of Squares & $\mathrm{df}$ & $\mathrm{F}$ & Significance* \\
\hline Mission, Vision and Goals & 1.248 & 1 & 3.587 & $.030 *$ \\
School Culture & .463 & 1 & 2.015 & .136 \\
Shared Responsibility & 1.283 & 1 & 4.627 & $.011 *$ \\
Leadership Practices & 1.283 & 1 & 4.627 & .112 \\
& & & &
\end{tabular}

The ANOVA results for the principals' years of experience in their school results show two DLRS dimensions with significant differences at the $\mathrm{p} \leq .05$ level. Shared Responsibility had a significance value of $\mathrm{p}=.011$ and Mission, Vision and Goals had a significance value of $\mathrm{p}=.030$. These values show that there were significant differences between respondents, but a post hoc test was needed to determine which groups had the difference. Table 11 shows the 
results for the post hoc Tukey test for the comparison of the years of experience in the school and the DLRS dimension of Shared Responsibility. The table shows categories for the years of experience in their school, the difference between their means and significance. The mean difference is used to calculate the significance level of the two groups.

Table 11

Post Hoc Comparison for Years of Experience in their School and Shared Responsibility

\begin{tabular}{lllc}
\hline & & Mean Difference (I-J) & Significance* \\
\hline \multirow{3}{*}{3 or less } & 4 to 6 & -0.214 & $0.013^{*}$ \\
& 7 or more & -0.150 & $0.046^{*}$ \\
4 to 6 & 3 or less & 0.214 & $0.013^{*}$ \\
& 7 or more & 0.063 & 0.610 \\
7 or more & 3 or less & & $0.046^{*}$ \\
& 4 to 6 & -0.063 & 0.610 \\
\hline$* p<.05$ & & &
\end{tabular}

Principal respondents with 4 to 6 years of experience in their school showed a significant difference for their distributed leadership readiness with the principal respondents with less than 3 years of experience in their school and the principal respondents with 7 or more years of experience in their school for the DLRS dimension of Shared Responsibility.

The post hoc comparison using a Tukey test shows that there is significant difference between two different pairs of the groups. The means and number of respondents from Appendix $\mathrm{G}$ are noted for each group. Principals with 4 to 6 years of experience in their school $(\bar{X}=3.53, \mathrm{n}=46)$ and 3 or less years of experience in their school $(\bar{X}=3.31, \mathrm{n}=55)$ showed a significant difference with a significance level of .013. Principals with 7 or more years of experience in their school $(\bar{X}=3.46, \mathrm{n}=97)$ and 3 or less years of experience in their school $(\bar{X}=3.31, \mathrm{n}=55)$ showed a significant difference with a significance level of .046 . There were no 
significant differences between the 4 to 6 years of experience in their school $(\bar{X}=3.53, \mathrm{n}=46)$ and 7 or more years of experience in their school $(\bar{X}=3.46, \mathrm{n}=97)$.

Table 12 shows the results for the post hoc Tukey test for the comparison of the years of experience in education and the DLRS dimension Mission, Vision and Goals. The table shows categories for the years of experience in school, the mean difference and the significance. The mean difference is used to calculate the significance level of the two groups.

\section{Table 12}

Post Hoc Results for Years of Experience in School and Mission, Vision, and Goals

\begin{tabular}{lccc}
\hline & & $\begin{array}{c}\text { Mean } \\
\text { Difference (I-J) }\end{array}$ & Significance* \\
\hline \multirow{3}{*}{ or less } & 4 to 6 & -0.135 & 0.242 \\
& 7 or more & -0.188 & $0.022^{*}$ \\
4 to 6 & 3 or less & 0.135 & 0.242 \\
& 7 or more & -0.053 & 0.755 \\
7 or more & 3 or less & 0.188 & $0.022^{*}$ \\
& 4 to 6 & 0.053 & 0.755 \\
\hline$* p<.05$ & & &
\end{tabular}

Principal respondents with 7 or more years of experience in their school showed a significant difference with principal respondents who had less than 3 years of experience in their school for their distributed leadership readiness for the DLRS dimension of Mission, Vision and Goals.

The post hoc comparison using a Tukey test showed that there is significant difference between principals with 7 or more years of experience in the school $(\bar{X}=3.41, \mathrm{n}=97)$ and 3 or less years of experience in the school $(\bar{X}=3.23, \mathrm{n}=55)$. There were no significant differences between the 4 to 6 years of experience $(\bar{X}=3.36, n=46)$ and the other two groups. The means and number of respondents from Appendix G are noted for each group. 
The ANOVA results allow the null hypothesis to be rejected and allow the alternative hypothesis to be accepted. The findings show that there were significant differences between the distributed leadership readiness of West Virginia principal respondents and years of experience in their school.

The null Hypothesis for this question and programmatic level was:

$\mathrm{H}_{0}$ : There is not a significant relationship between programmatic level and the distributed leadership readiness of West Virginia principals.

The alternative hypothesis for this question and programmatic level was:

$\mathrm{H}_{\mathrm{a}}$ : There is a significant relationship between programmatic level and the distributed leadership readiness of West Virginia principals.

Table 13 presents the ANOVA findings for the demographic factor of programmatic level.

Table 13

ANOVA Results for Programmatic Level and DLRS Dimensions

\begin{tabular}{lcccc}
\hline \multicolumn{1}{c}{ Dimension } & Sum of Squares & $\mathrm{df}$ & $\mathrm{F}$ & Significance* \\
\hline Mission, Vision and Goals & .048 & 1 & .133 & .876 \\
School Culture & .230 & 1 & .989 & .374 \\
Shared Responsibility & 1.096 & 1 & 3.926 & $.021^{*}$ \\
Leadership Practices & .020 & 1 & .051 & .951 \\
\hline$* p<.05$ & & & &
\end{tabular}

The ANOVA results for programmatic level shows one DLRS dimensions with significance differences at the $\mathrm{p} \leq .05$ level. Shared Responsibility had a significance value of $\mathrm{p}=.021$. This value shows that there was a significant difference between respondents, but a post hoc test was needed to determine which groups had the difference. Table 14 shows the results 
for the post hoc Tukey test for the comparison of the programmatic level and the DLRS dimension of Mission, Vision and Goals. Table 14 shows the categories for the programmatic level, the difference between their means and the significance. The mean difference is used to calculate the significance level of the two groups

Table 14

Post Hoc Results for Programmatic Level and Shared Responsibility

\begin{tabular}{lccc}
\hline & & $\begin{array}{c}\text { Mean Difference } \\
(\mathrm{I}-\mathrm{J})\end{array}$ & Significance* $^{*}$ \\
\hline \multirow{3}{*}{ Early Learning } & Middle & 0.068 & 0.613 \\
& High & 0.184 & $0.016^{*}$ \\
& & & \\
Middle & Early Learning & -0.068 & 0.613 \\
& Adolescent & 0.116 & 0.358 \\
Adolescent & Early Learning & -0.184 & $0.016^{*}$ \\
& Middle & -0.116 & 0.358 \\
\hline$* p<.05$ & & &
\end{tabular}

Early learning (PreK-5) principal respondents showed a significant difference with adolescent (9-12) principal respondents for their distributed leadership readiness for the DLRS dimension of Shared Responsibility.

The post hoc comparison using a Tukey test shows that there is significant difference between two groups. The means and number of respondents from Appendix G are noted for each group. Principals of the programmatic levels of Early learning $(\bar{X}=3.49, n=119)$ and Adolescent $(\bar{X}=3.31, \mathrm{n}=44)$ showed a significant difference with a significance level of .016 . There were no significant differences between the Middle $(\bar{X}=3.42, \mathrm{n}=35)$ and the other two. The ANOVA results allow the null hypothesis to be rejected and allow the alternative hypothesis to be accepted. The findings show that there were significant differences between the distributed leadership readiness of West Virginia principal respondents and programmatic level. 


\section{Summary of Findings}

This study sought to determine the relationship between the distributed leadership readiness of West Virginia principals and their perceptions of selected school-based committees which influence leadership in their schools. The demographic information about the respondents is presented first.

- $\quad$ There were 198 West Virginia principal respondents to the survey (29.3\%).

- The largest group of principal respondents were female (63\%), with 7 or more years of experience in education (99\%), with 7 or more years of experience in their current school (49\%), and at the early learning (PreK-5) programmatic level (60\%).

- Twenty-five of 40 items of the DLRS items had a mean higher than 3.38 and were considered to have a high mean, indicating that the principal respondents are ready for distributed leadership. (Research Question 1)

- School Culture had the highest mean (3.56) of the four DLRS dimensions. (Research Question 1)

- West Virginia principal respondents perceived that three school-based committees have a high influence on the leadership of the school: school leadership team $(\bar{X}=3.43)$, school curriculum team $(\bar{X}=3.42)$, and faculty senates $(\bar{X}=3.41)$. (Research Question 2$)$

- West Virginia principals' responses showed a significant statistical relationship at the $\mathrm{p} \leq .05$ level between all seven of the school-based committees and all four of the DLRS dimensions. (Research Question 3)

- The School Curriculum Team had strong positive relationships at the $\mathrm{p} \leq .05$ level with all four dimensions of the DLRS, indicating that the principal respondents perceived this 
school-based committee to be related to their distributed leadership readiness. (Research Question 3)

- Female principal respondents showed a significant difference with the male principal respondents in their distributed leadership readiness level for the DLRS dimensions of School Culture ( $\mathrm{p}=.005)$ and Shared Responsibility ( $\mathrm{p}=.024)$. (Research Question 4)

- No statistical tests could be completed on the survey data to reject or accept the hypotheses for the demographic factor of the principals' years of experience in education since 196 out of 198 had 7 or more years of experience in education. (Research Question 4)

- Principal respondents with 7 or more years of experience in their school showed a significant difference $(\mathrm{p}=.022)$ with principal respondents who had less than 3 years of experience in their school for their distributed leadership readiness for the DLRS dimension of Mission, Vision and Goals. (Research Question 4)

- Principal respondents with 4 to 6 years of experience in their school showed a significant difference for their distributed leadership readiness with the principal respondents with less than 3 years of experience in their school $(\mathrm{p}=.013)$ and those with 7 or more years of experience in their school $(\mathrm{p}=.046)$ for the DLRS dimension of Shared Responsibility. (Research Question 4)

- Early learning (PreK-5) principal respondents showed a significant difference $(\mathrm{p}=.016)$ with adolescent (9-12) principal respondents for their distributed leadership readiness for the DLRS dimension of Shared Responsibility. (Research Question 4) 


\section{Chapter 5}

\section{Summary, Conclusions, Discussion, and Recommendations}

This chapter includes a summary, conclusions, discussion and recommendations for practice and research.

\section{Summary}

The purpose of this study was to determine the relationship between the distributed leadership readiness of West Virginia principals and their perceptions of selected school-based committees which influence leadership in their schools. The study sought to answer the following research questions: 1) What is the distributed leadership readiness of West Virginia principals? 2) What are West Virginia principals' perceptions of selected school-based committees which influence leadership in their schools? 3) What is the relationship between the distributed leadership readiness of West Virginia principals and their perceptions of selected school-based committees which influence leadership in their schools? 4) Is there a difference between specific demographic characteristics of principals and their distributed leadership readiness?

Principals from all of the state's 674 schools were surveyed using the Distributed Leadership Readiness Scale (see Appendix A) and the School-Based Committee Influence Survey (see Appendix B). The DLRS was used to measure the distributed leadership readiness of the principals. The DLRS contained 40 items and used a 4 point Likert scale asking principals if the item occurred continually to rarely/never in the school. The DRLS grouped the items into 4 dimensions of distributed leadership. Gordon (2005) tested the DLRS and found it to be valid and reliable. 
The second survey was developed based on West Virginia statutes and laws that established seven school-based committees which can influence the leadership of the school. The School-Based Committee Influence Survey had 7 items that used a 4 point Likert scale and asked the principals to rate each item from strong influence to no influence. This survey was used to collect principal perceptions of the influence of these school-based committees. The survey was examined by a panel of legal experts for content validity and after some minor changes, determined to be valid. After the survey closed, the results from the respondents were used to test for internal consistency with Cronbach's Alpha and determined the survey to be reliable.

The principals of the 674 schools in West Virginia were provided an introductory letter (Appendix E) in a brief email, a link for the survey and a request to participate in July of 2015. This survey was conducted using the Qualtrics online software. It included the Distributed Leadership Readiness Scale (DLRS), demographic items, and the School-Based Committee Influence Survey. The demographic items included gender, years of experience in education, years of experience in their school, and programmatic level of the principals.

The survey responses were collected during a two week window and 198 principals submitted a completed survey for a return rate of $29.3 \%$. This was above the expected return rate, but still short of the average for an online survey sent out by email.

Research Question 1: What is the distributed leadership readiness of West Virginia principals? Responses for all forty DLRS items were used to calculate the mean scores to describe the results and standard deviations to show the distribution of the responses. Means and standard deviations were also calculated for the four dimensions. A high mean shows a higher readiness for distributed leadership. The results were: 
- Twenty-five of 40 items were considered to have high means

- Two dimensions, School Culture and Shared Responsibility were considered to have high means.

Research Question 2: What are West Virginia principals' perceptions of selected schoolbased committees which influence leadership in their schools? The mean and standard deviation were calculated for each item of the School-Based Committee Influence Survey. A high mean shows a higher perceived influence on leadership. The results were:

- School leadership team, school curriculum teams, and faculty senates all had means above the total mean value and were considered to have high mean scores.

Research Question 3: What is the relationship between the distributed leadership readiness of West Virginia principals and their perceptions of selected school-based committees which influence leadership in their schools? A Pearson $r$ correlation was used to measure the relationship between the means for the DLRS dimensions and the means of the School-Based Committee Influence survey items. A correlation shows the strength and significance level of the relationship between a paired set of means. The results were:

- All of the 28 relationships' significance levels were below the p-value of .01 and were statistically significant.

- There were 5 strong positive relationships, 11 moderate positive relationships, and 12 weak positive relationships.

- The School Curriculum Team had a strong positive relationship with all four of the DLRS dimensions.

Research Question 4: Is there a difference between specific demographic characteristics of principals and their distributed leadership readiness? The means scores and standard 
deviations from the DLRS dimensions were used to determine if there were any significant differences between them and the demographic factors. The demographic factors used in this analysis were gender, years of experience in education, years of experience in the school and programmatic level. A One-Way Analysis of Variance (ANOVA) was used to determine if there were any significant differences and to test the hypotheses for this research question. When a significant difference is found, the ANOVA results signify that a difference exists. When more than two groups were compared, the ANOVA results do not specify the groups with the significant difference. A post hoc test was then run to determine the groups with significant differences. The results were:

- Female principal respondents showed a significant difference with the male principal respondents in their distributed leadership readiness for the DLRS dimensions of School Culture and Shared Responsibility.

- Principal respondents with 7 or more years of experience in their school showed a significant difference with principal respondents who had less than 3 years of experience in their school for their distributed leadership readiness for the DLRS dimension of Mission, Vision and Goals.

- Principal respondents with 4 to 6 years of experience in their school showed a significant difference for their distributed leadership readiness with the principal respondents with less than 3 years of experience in their school and those with 7 or more years of experience in their school for the DLRS dimension of Shared Responsibility.

- Early learning (PreK-5) principal respondents showed a significant difference $(\mathrm{p}=.016)$ with adolescent (9-12) principal respondents for their distributed leadership readiness for the DLRS dimension of Shared Responsibility. 


\section{Conclusions}

The results of this study show that West Virginia principal respondents are ready for distributed leadership. The principal respondents see a relationship with the selected schoolbased committees and their distributed leadership readiness. The school leadership team, school curriculum team, and faculty senate were perceived to have more influence on the leadership of the school. The results showed the school curriculum team is perceived to have a strong relationship to the perceived level of distributed leadership readiness. The results also show that differences existed among some of the demographic factors and perceived distributed leadership readiness with some of the DLRS dimensions. Male and female principals differed in regards to School Culture and Shared Responsibility. Those principals having greater experience perceived the dimension of Mission, Vision, and Goals and Shared Responsibility as more strongly related to their distributed leadership readiness, as comparted to less experienced principals. Also, principals in elementary school perceived Shared Responsibility as more related to their distributed leadership readiness.

\section{Discussion}

This data collection window for this study was July 1, 2015 to July 14, 2015 with a response rate of $29.3 \%$. During this time period many West Virginia principals were not under contract and a long holiday weekend started on the third day of the survey window. Despite these two factors, the response rate was much higher than expected. My expectations for this survey were for a $20 \%$ response rate, half of the average return rate of $40 \%$ for an online survey delivered through email (Survey Monkey, 2011). This researcher believes the response rate may have been higher than expected because principals have an interest in the topic of distributed 
leadership readiness and its relationship to these school-based committees. Conducting this study during a different time of year could possibly produce a higher return rate.

More female (63\%) principals responded to this survey than the male principals and more early learning (PreK-5) principals responded than the other programmatic levels. These numbers are very similar to the demographic breakdown of the principals in West Virginia schools. According to the West Virginia Department of Education, females make up $61 \%$ of the principals and the early learning (Prek-5) principals make up 61\% for their programmatic level (personal communication, July 27, 2015). The similarity between these two demographic factors of the respondents and the population provides additional reasons of why the results could be generalized for this study. This could allow for the results of this study to be applied to all West Virginia principals.

Twenty-five of the 40 items for the DLRS had high mean scores. This could have occurred because the principals were self-reporting their perceptions and the survey only collected responses from the principals. These two factors could have caused the results to be inflated. The results of this study are similar to the results of Terrell (2010) when he used the DLRS to collect responses from principals and teachers. Terrell reports but does not discuss the high means that he got from the respondents, as in this study. In another study using the DLRS, the results showed lower means for the principal and teacher respondents (Zinke, 2013). When participants are self-reporting about their own school, the respondents may rate the items higher than other members of the organization. One other issue could be that principals may not fully understand the concept of distributed leadership and this may have caused inflated responses for some of the items. 
The DLRS dimension of School Culture had the highest mean score. School culture influences all aspects of a school (Saphier \& King, 1985) and the principals in this study perceived it to have the most influence on the distributed leadership readiness of their schools. Distributed leadership uses individuals and groups of people working together to take on leadership roles within the school. School Culture has been rated high in other studies using the DLRS. Respondents of the DLRS in a study by Terrell (2010) rated it as the highest dimension, as did the elementary school respondents for Christy (2005). Sally (2002) found that a positive culture in a school can add a sense of purpose for staff, yet a negative culture can have the opposite impact. The importance of a positive school culture cannot be overlooked for distributed leadership implementation. For others to assume leadership roles, staff members need to be able to work together and trust each other. I think school culture should be a focus for schools working to implement distributed leadership.

For distributed leadership to be implemented, the DLRS dimension with the lowest mean score would also need to be present. Leadership Practices was not only rated the lowest in this study, four additional studies using the DLRS had this dimension rated the lowest (Christy, 2008; Gordon, 2005; Terrell, 2010; Zinke, 2013). A few items within this dimension are about professional development and central office support, but the majority of the items are about teacher leadership roles. These items cover time and resources for leadership roles, along with available leadership roles and who can assume these roles. With all of these studies showing similar results, I believe it may show a significant weakness in the schools. The reason for this weakness needs to be further examined and addressed. In this study, the school-based committees are in place, but the principal respondents did not view them as providing enough leadership opportunities. As schools prepare to implement distributed leadership, this deficit 
must be addressed. For distributed leadership to work, teachers need to have leadership roles to fill, be trained to take on those roles, and be provided the resources to perform effectively in these roles.

The School Curriculum Team had the strongest correlations with all of the DLRS dimensions. The purpose of the school curriculum team is to provide professional opportunities for teachers and other staff, to have a direct voice for the operation of the school (West Virginia Code $§ 18-5 A-6,2014)$. This school-based committee includes the principal, counselors, and at least three teachers. This team should be working closely with critical functions of the school by focusing on curriculum, assessment, and instruction (West Virginia Code §18-5A-6, 2014). Research has shown that involving teachers in important school decisions has a measurable impact in student achievement (Waters et al., 2003). This team should make data driven decisions for the purpose of improving student learning. For many schools, this team may be meeting more often than the other school-based committees on the survey. Their involvement with many of the critical functions of the school and other customary meetings could strengthen relationships with the DLRS dimensions. The principal respondents of this study indicated this committee is influencing the leadership of their schools. This finding may show that the school curriculum team is creating "a culture of shared decision making" as stated in West Virginia WV Code $§ 18-5 A-6(b)(1)$.

The seven school-based committees showed a statistically significant relationship with the dimensions of the DLRS. The relationship of the principal perceptions of the DLRS dimensions and school-based committees was a surprise to the researcher. These school-based committees may be influencing the distributed leadership readiness of West Virginia principals. 
If this is true, existing school-based committees could be used for implementing distributed leadership in West Virginia Schools.

Three of the school-based committees had high means: School Leadership Team, School Curriculum Team and Faculty Senate. Four out of the seven school-based committees had low mean scores and the researcher did not expect the Local School Improvement Council (LSIC) to be in this group. The three committees with high mean scores, have integral roles for the student achievement in the school. These committees involve staff members in the leadership of the school. The LSIC had the second to the lowest mean score. This committee reviews discipline data, submits written recommendations to the local school board annually, encourages involvement of the school community and are involved with the strategic planning of the school (West Virginia Code $§ 18-5 \mathrm{~A}-2,2014)$. The committee members, along with its assigned tasks should make the LSIC an essential school committee. This group brings together a wide variety of stakeholder groups and must meet at least once every nine weeks during the school year. This committee is run by the elected chair, who also sets the agendas for the meetings. The low mean of this committee makes the researcher wonder if the LSIC is being utilized fully in schools.

Female principal respondents showed a significant difference with male principal respondents in their distributed leadership readiness in the DLRS dimensions of School Culture and Shared Responsibility. One area of weakness for this study was the lack of other studies to support these findings. For the dimension of school culture, the significance level was .005 and this seemed to be a strong finding of the study. The other studies utilizing the DLRS did not compare the distributed leadership readiness of the demographic groups. One study was found that compared female and male principals with distributed leadership and found that females 
were better at developing people (Grant, 2011). Developing people aligns with some items in the two DLRS dimensions, but not enough to support the finding of this study.

The results of this study showed that principals in elementary schools' distributed leadership readiness, within the dimension of Shared Leadership, was significantly different than the distributed leadership readiness of high school principals. Another study that used the DLRS discovered that elementary schools showed a higher distributed leadership readiness than middle schools (Christy, 2008). Middle schools and high schools have students changing classrooms and teachers are responsible for their specific areas of expertise. This can create an isolation that does not encourage collaboration. Although elementary schools still have teachers isolated, this does not seem to hinder the teachers working together in the elementary schools included in the study. This could be due to the fact that the nature of an elementary school tends to be a nurturing and caring culture (Christy, 2008). These factors may allow elementary schools staff members to trust each other and collaborate.

\section{Recommendations for Policy}

The school-based committees should be examined by West Virginia Legislature and West Virginia Department of Education for how they are influencing schools. The principal respondents reported that these committees influenced them, but this research did not indicate if this influence was positive or negative. The Office of Educational Performance Audits checks for these committees when they perform school visits, but this check is only to see if the committees are present in the school. The WVDE should evaluate these committees by reviewing each for their assigned members, roles, and tasks. This evaluation should look for any overlap between committees and if all the committees are still needed. Further examination could be conducted to see if these committees are filling needed roles in schools and if they need 
to be adjusted for current demands. Schools have changed since some of these committees were originally implemented and they may not meet the current needs of schools. The goal of this examination would be to show if all the committees are still needed and if any changes to the committees would be beneficial to the schools.

\section{Recommendations for Practice}

The West Virginia Department of Education should provide resources to support county school systems with distributed leadership. The results of the study showed that the principal respondents were ready for distributed leadership. Statewide support is critical to provide school systems with the tools needed for distributed leadership implementation. Focus groups should be used to start the process and gather effective strategies which are currently being used in West Virginia schools. The next step in the process would be to provide trainings and resources for counties to use with their schools.

County school systems need to provide distributed leadership professional development sessions for their principals. Principals have specific needs to be addressed. As stated previously in this study, the demands of the principal's job have continually increased. These trainings can focus on distributing leadership in their schools, along with ways to build structures for an effective distributed leadership model. Along with the trainings, principals need to be provided time to collaborate with other principals to share their knowledge and practices.

Principals cannot be expected to implement a distributed leadership model without the support of their central office administrators and their fellow principals.

Professional development opportunities need to be provided to schools in the area of leadership development. The findings of this study showed that the DRLS dimension of Leadership Practices had the lowest. The DLRS items within that dimension were statements 
about leadership opportunities in the school and professional development. To increase the leadership capacity of the school, professional development must be provided. Building the leadership capacity of the school would provide the necessary skills to implement an effective distributed leadership model. There should also be a focus on structures to provide the necessary time and resources to school leaders. The principals' involvement would be critical to the process and also provide an opportunity to increase distributed leadership knowledge.

Teachers need to be provided more opportunities to fill leadership roles in the school. The school-based committees used in this study provide leadership opportunities for teachers, but do not provide enough roles for teacher leadership. In schools, other committees and groups need to be utilized to provide leadership roles. Copland (2003) found that the engagement of the staff in the school improved the leadership and allowed for more involvement of the staff in the decision making of the schools. Grade level teams, departmental teams, and professional learning communities are examples of groups that can enable more teachers to assume leadership roles within the school. This engagement must coincide with the critical functions of curriculum, assessment and instruction. The role of teachers in the leadership process is critical for a school to be successful.

Providing leadership opportunities to more stakeholder groups, especially parents and students, would also be beneficial to the distributed leadership of schools. These critical groups can be left out of the leadership process in schools. These groups provide a different perspective about what is happening in schools and would help identify weaknesses to be addressed. Parent representatives are a part of the Local School Improvement Council and students can be included for schools with grades 7 to 12 . The role for these two groups, along with community members, should be expanded to increase their opportunities for leadership roles. 


\section{Recommendations for Future Research}

Conducting this study at a different time of the year could provide a higher return rate for the survey. Having more principal responses would provide additional insights into the relationship between the school-based committees and the distributed leadership readiness of West Virginia Schools. An increased response would also allow for the results to be generalized for the state.

Conducting the study with additional groups as respondents would also provide different insights into this relationship. Inviting assistant principals, teachers, professional staff, students, central office staff, parents, and/or community members to respond would provide a robust data set to be analyzed. These additional responses would provide a better understanding of the relationship between distributed leadership readiness and perceived influence of the school-based committees. These additional groups would provide a more complete picture of the schools.

Further studies utilizing qualitative case studies could be completed in West Virginia schools focusing on how the school-based committees are utilized. This would provide a more in-depth look at what was happening in these schools, along with how these committees are functioning. By identifying the structures that are in place, the findings may provide some best practices for principals to use with the school-based committees in their respective schools. This case study could also provide a clearer picture of the school-based committee's implementation and influence in the school. Details about its impact on the school could be obtained along with insight into possible changes to the committees.

Case studies could be used in high performing schools where distributed leadership has been successfully implemented. This research could allow for analysis into what best practices exist for distributed leadership. By investigating in depth, it may be possible to see if a link 
exists between school performance and the distributed leadership elements currently implemented in the school. In addition, the findings could provide a distributed leadership model and implementation strategies for other schools.

One last qualitative case study could be used to examine the differences between principal's gender and his or her distributed leadership readiness. This study exposed a significant difference between females' and males' distributed leadership readiness within two dimensions of the DLRS. A closer examination of these differences could provide some findings into how females and males approach implementing distributed leadership in their schools. This information could supply a clearer understanding of the various practices necessary for the different genders to successfully implement distributed leadership in their schools.

Researching the Local School Improvement Council (LSIC) in West Virginia and how it is being used in schools could also be beneficial. This committee can influence the discipline of the school, community involvement, and the implementation of innovative practices. Further examination of the involvement of teachers, parents, and students with this committee may show how it is influencing distributed leadership in schools. Also, since this committee reports directly to the board of education, the board members should also be included to examine their beliefs about the committee. These groups could provide data to show how the LISC is being implemented, how it completes its assigned tasks, and how effective it is overall.

Lastly, an examination of other states' statutes and policies could be conducted to see if any other states have similar school-based committees. These states could then provide locations to replicate the study. 


\section{References}

Andrews, R., \& Soder, R. (1987). Principal instructional leadership and school achievement. Educational Leadership (44), 9-11. Retrieved from http://www.ascd.org/ASCD/pdf/journals/ed_lead/el_198703_andrews.pdf

Avolio, B. J., Walumbwa, F. O., \& Weber, T. J. (2009). Leadership: Current theories, research, and future directions. Annual Review of Psychology, 60, 421-449.

doi:10.1146/annurev.psych.60.110707.163621

Barth, R. (1986). On sheep and goats and school reform. Phi Delta Kappan, 68(4), 293-296. Retrieved from http://www.jstor.org/stable/20403338

Bass, B. M. (1999). Two decades of research and development in transformational leadership. European Journal of Work and Organizational Psychology, 8(1), 9-32. Retrieved from https://ucdenver.instructure.com/courses/333/files/28022/download

Bass, B. M., \& Riggio, R. E. (2006). Transformational Leadership (2nd ed.). Mahwah, NJ: Lawrence Erlbaum Associates.

Blasé, J., \& Blasé, J. (1999). Principals' instructional leadership and teacher development: Teachers' perspectives. Education Administration Quarterly, 35(3), 349-378. doi:10.1177/0013161X99353003

Boudreaux, W. (2011). Distributed leadership and high-stakes testing: Examining the relationship between distributed leadership and LEAP scores. (Doctoral Dissertation), Southeastern Louisiana University, Educational Leadership. Retrieved from ProQuest database UMI Number: 3482420 
Christy, M. (2008). A comparison of distributed leadership readiness in elementary and middle schools. (Doctoral Dissertation), University of Missouri, Education. Retrieved from ProQuest database UMI Number: 3371049

Coleman, J. S., Campbell, E. Q., Hobson, C. J., McPartland, J., Mood, A. M., Weinfeld, F. D., \& York, R. L. (1966). Equality of educational opportunity. Washington, DC: National Center for Educational Statistics. Retrieved from http://files.eric.ed.gov/fulltext/ED012275.pdf

Conley, D., \& Goldman, P. (1994, April). School responses to state-level restructuring legislation. Paper presented at the Annual Meeting of the American Educational Research Asociation, New Orleans. Retrieved from http://files.eric.ed.gov/fulltext/ED369176.pdf

Copland, M. A. (2003). Leadership of inquiry: Building and sustaining capacity for school improvement. Educational Evaluation and Policy Analysis, 25(4), 375-395. Retrieved from http://www.jstor.org/stable/3699583

Cotton, K. (2003). Principals and student achievement: What the research says. Alexandria, VA: Association for Supervision and Curriculum Development.

Creswell, J. W. (2008). Research design: Qualitative, quantitative, and mixed methods approaches (3rd ed.). Thousand Oaks: Sage.

Davis, M. W. (2009). Distributed leadership and school performance. (Doctoral Dissertation), The George Washington University, Education and Human Development. Retrieved from Proquest database UMI number: 3344534

DuFour, R., DuFour, R., \& Eaker, R. (2008). Revisiting professional learning communities at work: New instights for improving schools. Bloomington, IN: National Education Services. 
Edmonds, R. (1978, July). A discussion of the literature and issues related to effective schooling. St. Louis, MO: Paper prepared for the national conference on urban education. Retrieved from http://eric.ed.gov/?id=ED170394

Edmonds, R. R. (1982). Programs of school improvement: An overview. Washington DC: National Institution of Education. Retrieved from http://www.ascd.org/ASCD/pdf/journals/ed_lead/el_198212_edmonds.pdf

Ellerbee, W., \& Miller, S. (2000). A blueprint for achievement at Sacramento City Unified School District. Thrust for Educational Leadership, 29(4), 17-19.

Elmore, R. (2000). Building a new structure for school leadership. Washington, DC: The Albert Shanker Institute. Retrieved from http://www.shankerinstitute.org/sites/shanker/files/building.pdf

Field, A. (2005). Discovering statistics using SPSS. (2 ${ }^{\text {nd }}$ Ed.) London: Sage.

Fielder, F. E. (1967). A theory of leadership effectiveness. New York: McGraw-Hill.

Fricker, R., \& Schonlau, M. (2002). Advantages and disadvantages of internet research surveys: Evidence from the literature. Field Methods, 14(4), 347-67. Retrieved from http://www.schonlau.net/publication/02fieldmethods.pdf

Fullan, M. (2003). The moral imperative of school leadership. Thousand Oaks, CA: Corwin Press.

Gay, L., Mills, G., \& Airasian, P. (2009). Educational research: Competencies for analysis and applications. (9th ed.). Upper Saddle River, NJ: Pearson.

Gibb, C. A. (1968). Leadership. In E. Lindsey, \& E. Aronson, Handbook of Social Psychology (2nd ed., Vol. 4, pp. 295-283). Reading, MA: Addsion-Wesley. 
Gipson, F. M. (2012). Understanding effective program improvement schools through a distributed leadership task context model. (Doctoral Dissertation), Claremont Graduate University, Graduate Faculty of Education. Retrieved from Proquest database UMI number: 3504445

Glesne, C. (2006). Becoming qualitative researchers: An introduction. (3rd Ed.) Boston: Pearson, Allyn, \& Bacon.

Gordon, Z. (2005). The effect of distributed leadership on student achievement. (Doctoral Dissertation), Central Connecticut State University, Department of Educational Leadership, New Britain, CT. Retrieved from Proquest database UMI number: 0808597

Grady, M. L. (1990). The teaching principal. Research in Rural Education, 6(3), 49-52. Retrieved from http://jrre.vmhost.psu.edu/wp-content/uploads/2014/02/6-3_7.pdf

Grant, C. P. (2011). The relationship between distributed leadership and principal's leadership effectiveness in North Carolina. (Doctoral Dissertation), North Carolina State University, Educational Research and Policy Analysis. Retrieved from Proquest database UMI Number: 3463701

Gronn, P. (2002). Distributed leadership as a unit of analysis. The Leadership Quarterly, 13(4), 423-451. doi:10.1016/S1048-9843(02)00120-0

Hallinger, P., \& Heck, R. (1996). Reassessing the principal's contribution to school effectiveness: A review of the empirical research,1980 - 1955. Education Administration Quarterly, 32(1), 5-44. Retrieved from http://philiphallinger.com/oldsite/papers/SESI_review_reprint.pdf

Hallinger, P., \& Heck, R. (2009b). Distributed leadership in schools: Does system policy make a difference? In A. Harris, Distributed leadership: Studies in educational leadership 7 (pp. 
101-117). New York, New York: Springer Science and Business Media B.V. Retrieved from http://link.springer.com/chapter/10.1007\%2F978-1-4020-9737-9_6

Hallinger, P., \& Heck, R. H. (2010). Collaborative leadership and school improvement:

Understanding the impact on school capacity and student learning. School Leadership \& Management: Formerly School Organisation, 30(2), 95-110. Retrieved from http://www.ied.edu.hk/apclc/dowloadables/Publications/2010/Collaborative\%20leadershi p\%20and\%20school\%20improvement.pdf

Halverson, R. R. (2004). Accessing, documenting and communicating the spronesis of school leadership practice. American Journal of Education, 111(1), 90-122. Retrieved from http://www.jstor.org/stable/10.1086/424721

Harris, A. (2007). Distributed leadership: conceptual confusion and empirical reticence. International Journal of Leadership in Education, 10(3), 1-11. Retrieved from http://www.tandfonline.com/doi/abs/10.1080/13603120701257313

Harrison, N. (2008). The impact of distributed leadership on teachers. Indiana University. ProQuest, UMI Dissertation Publishing, 3189149.

Hatcher, R. (2005). The distribution of leadership and power in schools. British Journal of Sociology of Education, 26(2), 253-267. Retrieved from http://www.jstor.org/stable/30036061

Heck, R. H., \& Hallinger, P. (2009). Assessing the contribution of distributed leadership to school improvement and growth in math achievement. American Educational Research Journal, 46(3), 659-689. Retrieved from http://www.jstor.org/stable/40284858

Hersey, P., \& Blanchard, K. H. (1969). Life cycle theory of leadership. . Training and Development Journal, 23(5), 26-34. Retrieved from 
http://moodle.unitec.ac.nz/pluginfile.php/268977/mod_resource/content/1/Hersey\%20and \%20Blanchards\%20situational\%20leadership\%20theory.pdf

Hulpia, H., Devos, G., \& Rosseel, Y. (2009). The relationship between the perception of distributed leadership in secondary schools and teachers' and teacher leaders' job satisfaction and ogranizational commitment. School Effectiveness and School Improvement, 20(3), 291-317. Retrieved from http://www.academia.edu/241764/The_relationship_between_the_perception_of_distribu ted_leadership_in_secondary_schools_and_teachers_and_teacher_leaders_job_satisfactio n_and_organizational_commitment

Hulpia, H., Devos, G., \& Van Keer, H. (2009). The influence of distributed leadership on teachers' organizational commitment: a multilevle approach. The Journal of Educational Research, 103(1), 40-52. Retrieved from http://search.proquest.com.www.libproxy.wvu.edu/docview/619746782/fulltextPDF/E81 01A5F8BCE4F93PQ/1?accountid=2837

Jacobs, G. E. (2010). The relationship between distributed leadership as practiced by principals and the organizational commitment of teachers. (Doctoral Dissertation), Georgia Southern University, Jack N. Averitt College of Graduate Studies. Retrieved from http://digitalcommons.georgiasouthern.edu/cgi/viewcontent.cgi?article=1349\&context=et d

Kahn, D., \& L., K. \&. (1966). The social psycology of organizations. New York, NY: Wiley. Retrieved from https://www.tamu.edu/faculty/bergman/katzkahn1978.pdf

Kouzes, J. M., \& Posner, B. Z. (2007). The leadership challenge (4th ed). San Francisco, CA: Jossey-Bass. 
Leithwood, K. (2001). School leadership and educational accountability. International Journal of Educational Leadership, 3(4), 217-237.

Leithwood, K., Louis, K., Anderson, S., \& Wahlstrom, K. (2004). How leadership influences student learning. New York: Wallace Foundation. Retrieved from http://www.wallacefoundation.org/knowledge-center/school-leadership/keyresearch/Pages/How-Leadership-Influences-Student-Learning.aspx

Leung, K. B. (2008). The scope and pattern of distributed leadership and its effects on organizational outcomes in Hong Kong secondary schools. (Doctoral Dissertation), The Chinese University of Hong Kong. Retrieved from Proquest Database UMI Number: 3362977

Lezotte, L. W. (1991). Correlates of effective schools: The first and second generation. Okemos, MI: Effective Schools Products, LTD.

Lipman-Blumen, J. (1996). The Connective Edge. San Francisco, CA.

Lunenburg, F., \& Ornstein, A. (2004). Educational administration: concepts and practices (4th ed.). Belmont, CA: Wadsworth/Thompson Learning.

McLeod, S. A. (2008). Simply psychology; Qualitative quantitative. Retrieved from http://www.simplypsychology.org/qualitative-quantitative.html

Miller, L., \& Smith, K.. (1983). Handling nonresponse issues. Journal of Extension, 21(5), 4550. Retrieved from http://www.joe.org/joe/1983september/83-5-a7.pdf

National Staff Development Council. (2001). Standards for staff development. Oxford, OH: National Staff Development Council.

Northouse, G. (2007). Leadership theory and practice (3rd ed.). Thousand Oaks, CA: Sage Publications. 
Onukwugha, P. (2013). Distributed leadership in schools, teacher practices, and student learning. University of Missouri, Educational Leadership. UMI Dissertation Publishing (3562449).

Ouchi, W. G., Cooper, B. S., Segal, L. G., \& DeRoche, T. (2003). Organization configuration and performance: The case of primary and secondary systems. UCLA, Anderson School of Management, Los Angeles, CA.

Phillips, D. (2013). Distributed leadership and the academic performance of International Baccalaureate (IB) World Schools. (Doctoral Dissertation), Keiser University, Educational Leadership. Retrieved from Proquest database UMI number:3558761

Policies [Def. 1] (n.d). In Oxford Dictionaries, Retrieved June 18, 2015 from http://www.oxforddictionaries.com/us/definition/american_english/policy.

Rice, O. K., \& Brown, S. W. (1994). West Virginia: A History (2nd Ed.). Lexington, KY: University Press of Kentucky.

Rivers, S. D. (2010). Leadership as a distributed phenomenon: A study of shared roles and 3rd grade student achievement. (Doctoral Dissertation), Capella University. Retrieved from ProQuest database UMI Number: 3412486

Robinson, V. M., Lloyd, C. A., \& Rowe, K. J. (2008). The impact of leadership on school outcomes: An analysis of the differential effects of leadership types. Educational Administration Quarterly, 44(5), 635-674. Retrieved from http://donnaelder.wiki.westga.edu/file/view/The+impact+of+leadership+on+student+outc omes+an+analysis+of+the+differential+effects+of+leadership+types.pdf 
Robinson, V., Lloyd, C., \& Rowe, K. (2008). The impact of leadership on student outcomes: An analysis of the differential effects of leadership types. Educational Administration Quarterly, 44(3), 635-674.

Sally, D. (2002). Co-leadership: Lessons from Republican Rome. California Management Review, 44(4), 84-99.

Saphier, J., \& King, M. (1985). Good seeds grow in strong cultures. Educational Leadership, 42(6), 67-74. Retrieved from http://www.ascd.org/ASCD/pdf/journals/ed_lead/el_198503_saphier.pdf

Sergiovanni, T. J. (1998). Leadership as pedagogy, capital developement and school effectiveness. International Journal of Leadership in Education, 1(1), 37-46. Retrieved from http://eric.ed.gov/?id=EJ577237

Shannon, G., \& Bylsma, P. (2007). The nine characteristics of high-performing schools: A research-based resource for schools and districts to assist with improving student learning. (2nd ed.). Olympia, WA: Office of Superintendent of Public Instruction. Smith, P. B., \& Peterson, M. F. (1998). Leadership, orgnaizations and culture: An event managment model. London: Sage.

Smith, R. W. (2001). Teacher efficacy, administrator efficacy, school culture, and leadership density. Louisiana State University and Agricultural and Mechanical College, The Department of Educational Leadership, Research. Retrieved from ProQuest database UMI Number: 3031767

Smith, R. W., Ross, M., \& Robichaux, R. (2004). Creation and validation of a measure of leadership density in elementary and middle schools. The Journal of Research for 
Educational Leaders, 2(2), 79-111. Retrieved from

http://www2.education.uiowa.edu/archives/jrel/fall04/Smith-Ross-Robichaux_0411.htm

Spillane, J. (2006). Distributed Leadership. San Francisco:Jossey-Bass.

Spillane, J., Halverson, R., \& Diamond, J. B. (2001). Investigating school leadership practice: A distributed perspective. Educational Researcher, 30(3), 23-28. Retrieved from http://www.jstor.org/stable/3594470

Spillane, J., Halverson, R., \& Diamond, J. B. (2004). Towards a theory of leadership practice: A distributed perspective. Journal of Curriculum Studies, 36(1), 3-34.

doi:10.1080/0022027032000106726

Stogdill, R. M. (1948). Personal factors associated with leadership: A lurvey of the literature. Journal of Psychology, 25, 35-71. doi:10.1080/00223980.1948.9917362

Survey Monkey. (2011). Smart survey design. Retrieved from http://s3.amazonaws.com/SurveyMonkeyFiles/SmartSurvey.pdf

Terrell, H. (2010). The relationship of the dimensions of distributed leadership in elementary schools of urban districts and student achievement. (Doctoral Dissertation), The George Washington University, The Graduate School of Education and Human Development. Retrieved from ProQuest database UMI Number: 3397678

Tyack, D., \& Hansot, E. (1986). Managers of virtue: Public school leadership in America, 18201980. New York: Basic Books, Inc.

United States Department of Education. (1983). A nation at risk: The imperative for educational reform. The National Commission on Excellence in Education. Washington, DC: United States Department of Education. 
United States Department of Education. (2002, January). No Child Left Behind Act of 2001. Public Law 107-110, 107th Congress. Retrieved from http://www.ed.gov/policy/elsec/leg/esea02/107-110.pd

Waters, T., Marzano, R., \& McNulty, B. (2003). Balanced leadership: What 30 years of research tells us about the effect of leadership on student achievement. Aurora, CO: Midcontinent Research for Education and Learning.

West Virginia State Board of Education. (2015). Policy 2460: Educatonal purpose and acceptable use of electronic resources, technologies and the internet. Charleston, WV: Author. Retrieved January 8, 2015, from http://apps.sos.wv.gov/adlaw/csr/readfile.aspx?DocId=23479\&Format=PDF

West Virginia State Board of Education. (2015). Policy 2510: Assuring quality education: Regulations for education programs. Charleston, WV: Author. Retrieved January 8, 2015, from http://apps.sos.wv.gov/adlaw/csr/readfile.aspx?DocId=25770\&Format=PDF

West Virginia Code §18-2E-5(b). (2014). Electronic county and school strategic improvement plans. Retrieved from http://www.legis.state.wv.us/wvcode/ChapterEntire.cfm?chap=18\&art=2E\&section=5

West Virginia Code §18-5A-2. (2014). Local school improvement councils; election. Retrieved from http://www.legis.state.wv.us/wvcode/Code.cfm?chap=18\&art=5A

West Virginia Code §18-5A-5. (2014). Public school faculty senates established; election of officers; powers and duties. Retrieved from http://www.legis.state.wv.us/wvcode/ChapterEntire.cfm?chap=18\&art=5A 
West Virginia Code §18-5A-6. (2014). Establishment of school curriculum teams; process for teacher collaboration to improve learning. Retrieved from http://www.legis.state.wv.us/wvcode/ChapterEntire.cfm?chap=18\&art=5A

West Virginia Code $§ 18 A-3-8$. (2014). County professional staff development councils. Retrieved from http://www.legis.state.wv.us/wvcode/ChapterEntire.cfm?chap=18a\&art=3\&section=8\#03

West Virginia Code §18A-3C-3. (2014). Comprehensive system for teacher induction and professional growth. Retrieved from http://www.legis.state.wv.us/wvcode/ChapterEntire.cfm?chap=18a\&art=3C

Yukl, G., \& Becker, W. (2007). Effective empowerment in organizations. Organization Management Journal, 3(3), 210-231. doi:10.1057/omj.2006.20

Zinke, A. (2013). The relationship between shared leadership, teacher self-efficacy, and student achievement. (Doctroal Dissertation), University of Southern Mississippi, Educational Leadership. Retrieved from Proquest database UMI Number: 35776363 


\section{Appendix A}

\section{Distributed Leadership Readiness Scale (DLRS)}

The following self-evaluation scale has been designed to provide a profile of your district/school's readiness in shared leadership practices. The scale is based on current research on school leadership designed to improve public school capacity to increase student academic achievement (i.e. Building a Structure for School Leadership, Richard Elmore, 2000).

The Distributed Leadership Readiness Scale (DLRS) is organized into five key dimensions of instructional leadership: Mission, Vision, and Goals; School Culture; Decision-Making; Evaluation and Professional Development; and Leadership Practices.

\section{Directions:}

Participants are encouraged to be as candid as possible when completing the scale. All individual responses will remain strictly confidential. Use the five-point scale from

'Continually' (4) to 'Rarely/Never' (1) to indicate how regularly the following statements apply to you and your school. Select 'N/A' if you do not have sufficient information to respond to the statement.

\section{Response Options:}

4 = Continually - the particular practice is well-established as a "standard operating procedure" in the school.

$3=$ Frequently - this practice is often observed in the school.

$2=$ Sometimes - this practice is intermittently observed in the school.

$1=$ Rarely/Never - this practice is rarely or never observed in school.

$\mathrm{N} / \mathrm{A}=$ Insufficient Information - insufficient information to respond to the statement.

\begin{tabular}{|c|c|c|c|c|c|}
\hline & 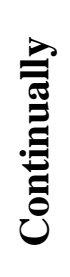 & 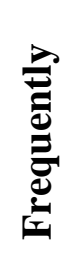 & 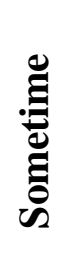 & 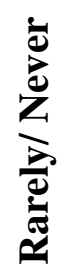 & 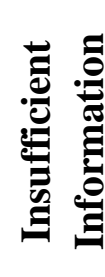 \\
\hline 1. The school has clearly written vision and mission statements. & 4 & 3 & 2 & 1 & N/A \\
\hline $\begin{array}{l}\text { 2. Teachers and administrators understand and support a } \\
\text { common mission for the school and can describe it clearly. }\end{array}$ & 4 & 3 & 2 & 1 & N/A \\
\hline $\begin{array}{l}\text { 3. If parents are asked to describe the school's mission, most } \\
\text { would be able to describe the mission clearly. }\end{array}$ & 4 & 3 & 2 & 1 & N/A \\
\hline $\begin{array}{l}\text { 4. If students are asked to describe the school's mission, most } \\
\text { would be able to describe the mission generally. }\end{array}$ & 4 & 3 & 2 & 1 & N/A \\
\hline 5. School goals are aligned with its mission statement. & 4 & 3 & 2 & 1 & N/A \\
\hline $\begin{array}{l}\text { 6. The school uses a school improvement plan as a basis to } \\
\text { evaluate the progress it is making in attaining its goals. }\end{array}$ & 4 & 3 & 2 & $\mathbf{1}$ & N/A \\
\hline $\begin{array}{l}\text { 7. Teachers and administrators collectively establish school } \\
\text { goals and revise goals annually. }\end{array}$ & 4 & 3 & 2 & 1 & N/A \\
\hline
\end{tabular}




\begin{tabular}{|c|c|c|c|c|c|}
\hline $\begin{array}{l}\text { 8. The school's curriculum is aligned with the state's academic } \\
\text { standards. }\end{array}$ & 4 & 3 & 2 & 1 & N/A \\
\hline $\begin{array}{l}\text { 9. Teachers and administrators have high expectations for } \\
\text { students' academic performance. }\end{array}$ & 4 & 3 & 2 & 1 & N/A \\
\hline $\begin{array}{l}\text { 10. Teachers and administrators share accountability for } \\
\text { students' academic performance. }\end{array}$ & 4 & 3 & 2 & 1 & N/A \\
\hline $\begin{array}{l}\text { 11. School and district resources are directed to those areas in } \\
\text { which student learning needs to improve most. }\end{array}$ & 4 & 3 & 2 & 1 & N/A \\
\hline $\begin{array}{l}\text { 12. The school is a learning community that continually } \\
\text { improves its effectiveness, learning from both successes and } \\
\text { failures. }\end{array}$ & 4 & 3 & 2 & 1 & N/A \\
\hline $\begin{array}{l}\text { 13. There is a high level of mutual respect and trust among the } \\
\text { teachers and other professional staff in the school. }\end{array}$ & 4 & 3 & 2 & 1 & N/A \\
\hline $\begin{array}{l}\text { 14. There is mutual respect and trust between the school } \\
\text { administration and the professional staff. }\end{array}$ & 4 & 3 & 2 & 1 & N/A \\
\hline $\begin{array}{l}\text { 15. The school administrator(s) welcome professional staff } \\
\text { members input on issues related to curriculum, instruction, and } \\
\text { improving student performance. }\end{array}$ & 4 & 3 & 2 & 1 & N/A \\
\hline $\begin{array}{l}\text { 16. The school supports using new instructional ideas and } \\
\text { innovations. }\end{array}$ & 4 & 3 & 2 & 1 & N/A \\
\hline $\begin{array}{l}\text { 17. The school's daily and weekly schedules provide time for } \\
\text { teachers to collaborate on instructional issues. }\end{array}$ & 4 & 3 & 2 & 1 & N/A \\
\hline $\begin{array}{l}\text { 18. School professionals and parents agree on the most effective } \\
\text { roles parents can play as partners in their child's education. }\end{array}$ & 4 & 3 & 2 & 1 & N/A \\
\hline $\begin{array}{l}\text { 19. The school clearly communicates the 'chain of contact' } \\
\text { between home and school so parents know who to contact when } \\
\text { they have questions and concerns. }\end{array}$ & 4 & 3 & 2 & 1 & N/A \\
\hline $\begin{array}{l}\text { 20. The school makes available a variety of data (e.g. student } \\
\text { performance) for teachers to use to improve student } \\
\text { achievement. }\end{array}$ & 4 & 3 & 2 & 1 & N/A \\
\hline $\begin{array}{l}\text { 21. Decisions to change curriculum and instructional programs } \\
\text { are based on assessment data. }\end{array}$ & 4 & 3 & 2 & 1 & N/A \\
\hline $\begin{array}{l}\text { 22. There is a formal structure in place in the school (e.g. } \\
\text { curriculum committee) to provide teachers and professional staff } \\
\text { opportunities to participate in school-level instructional decision- } \\
\text { making. }\end{array}$ & 4 & 3 & 2 & 1 & N/A \\
\hline $\begin{array}{l}\text { 23. The principal actively encourages teachers and other staff } \\
\text { members to participate in instructional decision-making. }\end{array}$ & 4 & 3 & 2 & 1 & N/A \\
\hline $\begin{array}{l}\text { 24. Professional staff members in the school have the } \\
\text { responsibility to make decisions that affect meeting school goals. }\end{array}$ & 4 & 3 & 2 & 1 & N/A \\
\hline $\begin{array}{l}\text { 25. The school provides teachers with professional development } \\
\text { aligned with the school's mission and goals. }\end{array}$ & 4 & 3 & 2 & 1 & N/A \\
\hline $\begin{array}{l}\text { 26. Administrators participate alongside teachers in the school's } \\
\text { professional development activities. }\end{array}$ & 4 & 3 & 2 & 1 & N/A \\
\hline
\end{tabular}




\begin{tabular}{|c|c|c|c|c|c|}
\hline $\begin{array}{l}\text { 27. The principal actively participates in his/her own } \\
\text { professional development activities to improve leadership in the } \\
\text { school. }\end{array}$ & 4 & 3 & 2 & 1 & N/A \\
\hline $\begin{array}{l}\text { 28. My supervisor and I jointly develop my annual professional } \\
\text { development plan. }\end{array}$ & 4 & 3 & 2 & 1 & N/A \\
\hline $\begin{array}{l}\text { 29. My professional development plan includes activities that } \\
\text { are based on my individual professional needs and school needs. }\end{array}$ & 4 & 3 & 2 & 1 & N/A \\
\hline $\begin{array}{l}\text { 30. Teachers actively participate in instructional decision- } \\
\text { making. }\end{array}$ & 4 & 3 & 2 & 1 & N/A \\
\hline $\begin{array}{l}\text { 31. Central office and school administrators work together to } \\
\text { determine the professional development activities. }\end{array}$ & 4 & 3 & 2 & 1 & N/A \\
\hline $\begin{array}{l}\text { 32. The principal is knowledgeable about current instructional } \\
\text { issues. }\end{array}$ & 4 & 3 & 2 & 1 & N/A \\
\hline \multicolumn{6}{|l|}{ 33. The principal's practices are consistent with his/her words. } \\
\hline $\begin{array}{l}\text { 34. Informal school leaders play an important role in the school } \\
\text { in improving the performance of professionals and the } \\
\text { achievement of students. }\end{array}$ & 4 & 3 & 2 & 1 & N/A \\
\hline $\begin{array}{l}\text { 35. The school has expanded its capacity by providing } \\
\text { professional staff formal opportunities to take on leadership } \\
\text { roles. }\end{array}$ & 4 & 3 & 2 & 1 & N/A \\
\hline $\begin{array}{l}\text { 36. Teachers who assume leadership roles in the school have } \\
\text { sufficient school time to permit them to make meaningful } \\
\text { contributions to the school. }\end{array}$ & 4 & 3 & 2 & 1 & N/A \\
\hline $\begin{array}{l}\text { 37. Teachers who assume leadership roles in the school have } \\
\text { sufficient resources to be able to make meaningful contributions } \\
\text { to the school. }\end{array}$ & 4 & 3 & 2 & 1 & N/A \\
\hline 38. Veteran teachers fill most leadership roles in the school. & 4 & 3 & 2 & 1 & N/A \\
\hline $\begin{array}{l}\text { 39. New teachers are provided opportunities to fill some school } \\
\text { leadership roles. }\end{array}$ & 4 & 3 & 2 & 1 & N/A \\
\hline $\begin{array}{l}\text { 40. Teachers are interested in participating in school leadership } \\
\text { roles. }\end{array}$ & 4 & 3 & 2 & 1 & N/A \\
\hline
\end{tabular}

\section{Demographic Information:}
a. Gender
$1=$ Female
$2=$ Male
b. Total years in education
$\mathbf{1}=$ less than 1
$\mathbf{2}=1-3$
$3=4-6$
$4=7$ or more
c. Total years in this school

$$
\begin{aligned}
& \mathbf{1}=\text { less than } 1 \\
& \mathbf{2}=1-3 \\
& \mathbf{3}=4-6 \\
& \mathbf{4}=7 \text { or more }
\end{aligned}
$$


d. Programmatic level

Please Select grade levels in your building

$\begin{array}{cl}\text { Pre-K } & \text { K } \\ 1 & 2 \\ 3 & 4 \\ 5 & 6 \\ 7 & 8 \\ 9 & 10 \\ 11 & 12\end{array}$




\section{Appendix B}

\section{School-based Committee Influence Survey}

DIRECTIONS: Each of these seven committees help distribute leadership in schools. The teachers or stakeholders are granted authority to make decisions and have input into various aspects of a school. Please rate the level of influence of each.

\begin{tabular}{|c|c|c|c|c|c|}
\hline & 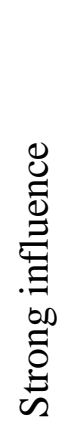 & 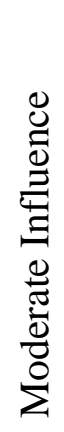 & 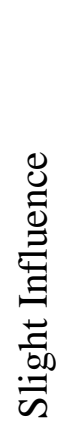 & 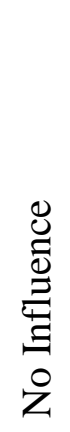 & 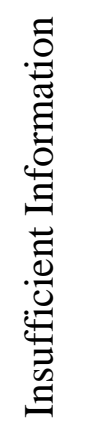 \\
\hline $\begin{array}{l}\text { Faculty senates allocate funds for academic materials, submit } \\
\text { recommendations for the master curriculum and can also nominate } \\
\text { outstanding educators for recognition. They also recommend beginning } \\
\text { teacher mentors, review the evaluation procedure, and comment on } \\
\text { sabbatical leave requests. They may nominate members for election to } \\
\text { the county staff development council and the LSIC. The faculty senate } \\
\text { may also make recommendations regarding assignment scheduling of } \\
\text { secretaries, clerks, aides, and paraprofessionals. They are to meet } 5 \\
\text { times a year. This group may elect to participate in the hiring process } \\
\text { for classroom teacher vacancies in the school or delegate the process to } \\
\text { a committee of no less than three members (WV Code } \$ 18-5 A-5, W V \\
\text { State Board Policy } 2510 \text { ). }\end{array}$ & 4 & 3 & 2 & 1 & $\mathrm{~N} / \mathrm{A}$ \\
\hline $\begin{array}{l}\text { Professional development councils have final authority to recommend } \\
\text { professional staff development for the county and represent each of the } \\
\text { programmatic levels of the county. They should contain between nine } \\
\text { and fifteen members (WV Code } \S 18 \mathrm{~A}-3-8 \text { ). }\end{array}$ & 4 & 3 & 2 & 1 & N/A \\
\hline $\begin{array}{l}\text { School curriculum teams have a direct voice in the operation of the } \\
\text { school, work to create a culture of shared decision making and involve } \\
\text { teachers in the process to improve student learning. They can be part of } \\
\text { curriculum implementation, assessments, and instructional strategies. } \\
\text { This team is composed of the principal, the counselor, and no fewer } \\
\text { than three teacher representatives (WV Code §18-5A-6). }\end{array}$ & 4 & 3 & 2 & 1 & N/A \\
\hline $\begin{array}{l}\text { Local school improvement councils review discipline data and } \\
\text { procedures yearly, submit written recommendations to the local school } \\
\text { board and meet with it annually. They encourage involvement of the } \\
\text { school community and are involved with the strategic planning of the } \\
\text { school. They must meet once every grading period (WV Code } \S 18-5 A-2 \text { ). }\end{array}$ & 4 & 3 & 2 & 1 & N/A \\
\hline
\end{tabular}




\begin{tabular}{|c|c|c|c|c|c|}
\hline $\begin{array}{l}\text { The school leadership team includes representatives from the LSIC, } \\
\text { the curriculum team, the technology team, professional learning } \\
\text { communities and parent/community organizations. Its } \\
\text { responsibilities are: analyze student performance data; review all } \\
\text { facets of the school's operation; review monitoring reports relevant } \\
\text { to school improvement; use self-study tools to determine priorities } \\
\text { for improvement; determine causes of deficits in student } \\
\text { performance and make recommendations for improvement; } \\
\text { collaborate with parents, staff, and county team to identify school } \\
\text { improvement goals, plan, implementation and monitoring; } \\
\text { recommend additional assistance to implement the } \\
\text { school improvement plan; collaborate with outside entities to } \\
\text { address student learning needs (WV Code } \$ 18-2 E-5(b) \& \text { WV } \\
\text { State Board Policy 2510). }\end{array}$ & 4 & 3 & 2 & 1 & $\mathrm{~N} / \mathrm{A}$ \\
\hline $\begin{array}{l}\text { Mentors, master teachers, academic coaches may provide support, } \\
\text { supervision or other professional development to employees for the } \\
\text { purpose of improving their professional practice (WV State Code } \\
\S 18 \mathrm{~A}-3 \mathrm{C}-3(\mathrm{j})(\mathrm{d})(5)) \text {. }\end{array}$ & 4 & 3 & 2 & 1 & N/A \\
\hline $\begin{array}{l}\text { The school technology team is required to develop a } \\
\text { comprehensive technology plan, which is part of the five-year } \\
\text { strategic plan (WV State Board Policy } 2460 \& 2510 \text { ). }\end{array}$ & 4 & 3 & 2 & 1 & N/A \\
\hline
\end{tabular}




\section{Appendix C}

School-Based Committee Influence Review Form

Directions to reviewer: Please read each item for accuracy. The URL for state code or policy has been provided with each. If the item is accurate as written, please place a check in the box "ACCURATE AS IS". If it is not accurate please correct.

School-Based Committee Influence Survey

DIRECTIONS (to PRINCIPAL): Each of these seven committees help distribute leadership in schools. The teachers or stakeholders are granted authority to make decisions and have input into various aspects of a school. Please rate the level of influence of each.

\begin{tabular}{|c|c|c|c|c|c|c|c|}
\hline & 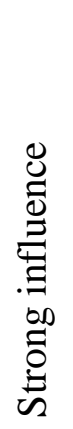 & 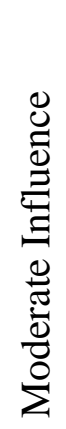 & 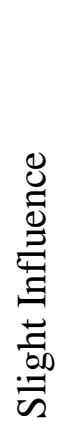 & 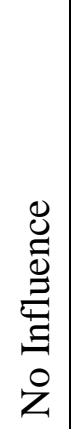 & 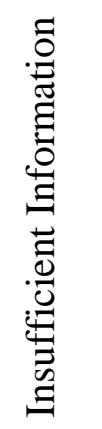 & 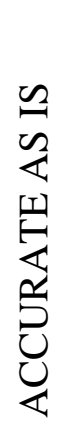 & CORRECTED VERSION \\
\hline $\begin{array}{l}\text { Faculty senates allocate funds for academic materials, } \\
\text { submit recommendations for the master curriculum and } \\
\text { can also nominate outstanding educators for recognition. } \\
\text { They also recommend beginning teacher mentors, } \\
\text { members for the LSIC and county staff development } \\
\text { council. They are to meet } 5 \text { times a year. This group may } \\
\text { elect to participate in the hiring process for classroom } \\
\text { teacher vacancies in the school or delegate the process to a } \\
\text { committee of no less than three members (WV Code } \S 18 \text { - } \\
5 \text { A-5, WV State Board Policy } 2510 \text { ). } \\
\text { http://www.legis.state.wv.us/wvcode/ChapterEntire.cfm?c } \\
\text { hap }=18 \& \text { art=5A\&section }=5\end{array}$ & 4 & 3 & 2 & 1 & N/A & & \\
\hline
\end{tabular}




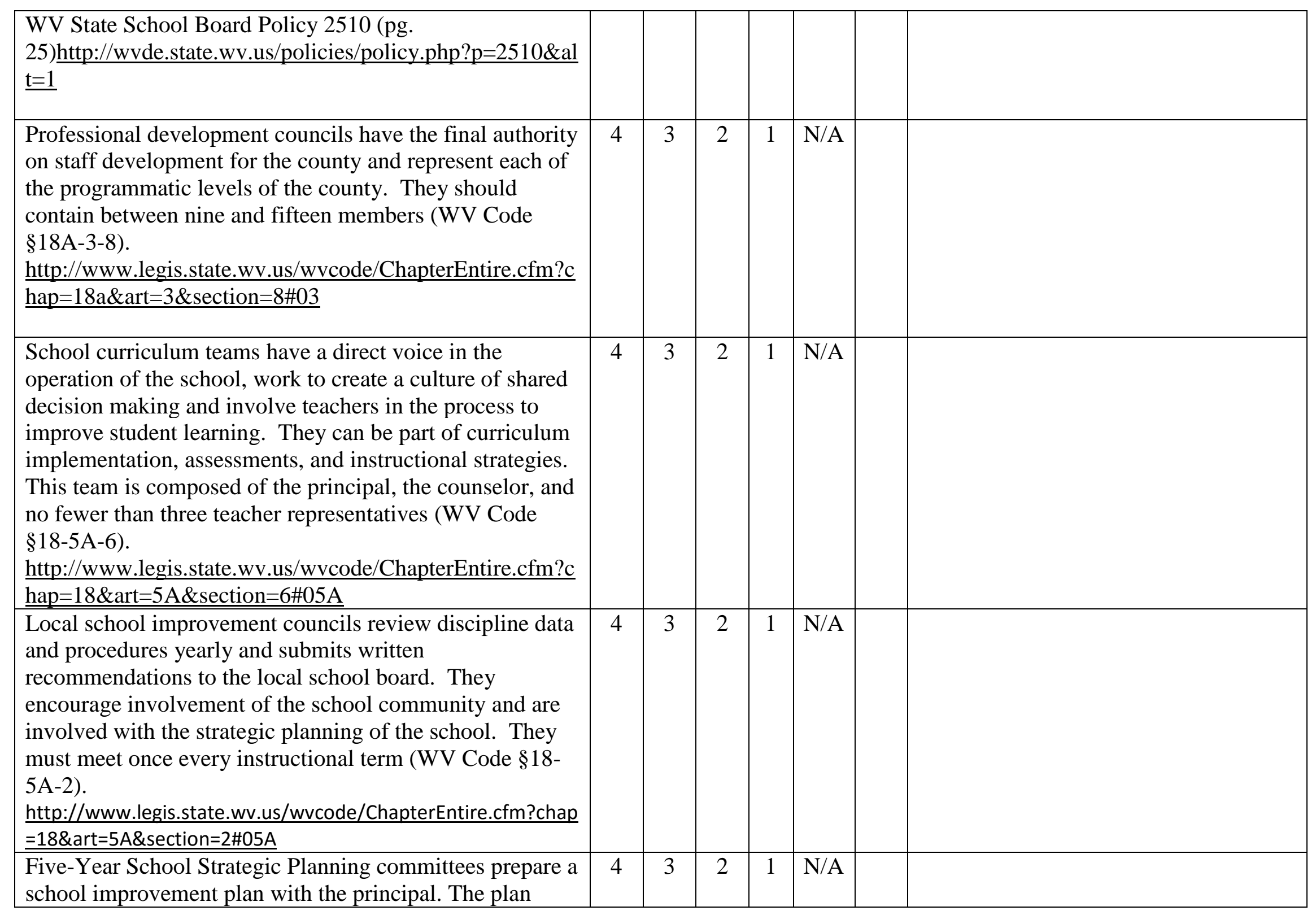




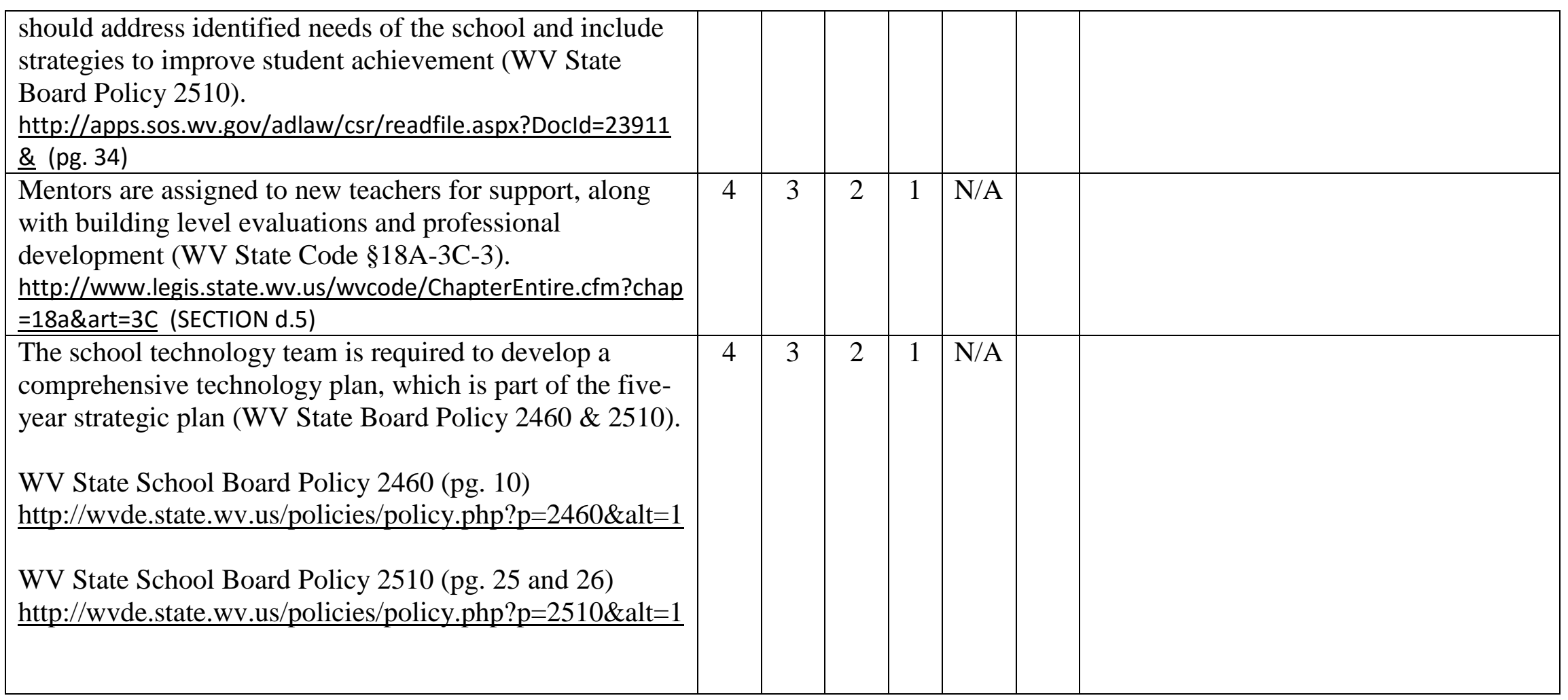




\section{Appendix D}

\section{Letter to Superintendent}

\section{WestVirginiaUniversity}

College of Education and Human Services

July 1,2015

Dear Superintendent:

In partial fulfillment of the educational leadership studies doctoral program at West Virginia University, I am required to conduct a research-based study. The purpose of my study is to identify a relationship, if any, between the distributed leadership readiness of West Virginia principals and their perceptions of selected school-based committees which influence leadership in their schools.

The purpose of this letter is to inform you I will soon be contacting by email the principals of your county and seeking their participation in the study by completing an electronic survey. The survey will take less than 10-15 minutes of their time. Participation is voluntary and there are no consequences for non-participation. Respondents may skip any questions they are not comfortable answering or may quit at any point and submit a partially completed questionnaire. Individual survey responses will be kept confidential. Survey results will not indicate the identity of the participants or their respective counties and schools. West Virginia University IRB has acknowledged this protocol.

Respondents are asked to complete the survey no later than July 14, 2015. If you have further questions contact me at plriddle1@gmail.com or (304) xxx-xxxx. Thank you for your assistance.

Sincerely,

Helen M. Hazi, Ph.D.

Professor and Committee Chairperson
Patrick L. Riddle II

Doctoral Candidate
Helen.Hazi@mail.wvu.edu Phone: 304-293-1885

Fax: 304-293-2279
Department of Curriculum \& Instruction/Literacy Program of Educational Leadership Studies 608 Allen PO Box 6122

Morgantown,'WV 26506-6122 


\section{Appendix E}

Principal Invitation Letter

\section{WestVirginiaUniversity}

College of Education and Human Services

July 1,2015

Dear Principal:

In partial fulfillment of the educational leadership studies doctoral program at West Virginia University, I am required to conduct a research-based study. The purpose of my study is to identify a relationship, if any, between the distributed leadership readiness of West Virginia principals and their perceptions of selected school-based committees which influence leadership in their schools.

The purpose of this letter is to invite you to participate in the study by completing an electronic survey. The survey will take less than 10-15 minutes of their time. Participation is voluntary and there are no consequences for non-participation. Respondents may skip any questions they are not comfortable answering or may quit at any point and submit a partially completed questionnaire. Individual survey responses will be kept confidential. Survey results will not indicate the identity of the participants or your respective schools. West Virginia University's Institutional Review Board acknowledgement of this project is on file. West Virginia University IRB has acknowledged this protocol.

The online survey can be accessed at the following site:

http://wvu.qualtrics.com/SE/?SID=SV_26pOkklTIMNwbaJ

If you have further questions contact me at plriddle1@gmail.com or (304) xxx-xxxx. Thank you for your assistance.

Sincerely,

Helen M. Hazi, Ph.D.

Patrick L. Riddle II

Professor and Committee Chairperson Doctoral Candidate

Department of Curriculum \& Instruction/Literacy

Helen.Hazi@mail.wvu.edu

Phone: 304-293-1885 Program of Educational Leadership Studies

Fax: 304-293-2279 Morgantown;'WV 26506-6122 


\section{Appendix F}

Approval Email to use the Distributed Leadership Readiness Scale

From: Jacobson, Larry [mailto:Larry.Jacobson@ct.gov]

Sent: Thursday, April 30, 2009 11:18 AM

To: Patrick Riddle

Subject: FW: Distributed Leadership

Patrick,

I have attached several documents regarding our Distributed Leadership Readiness Scale. The scale was originally used as part of a research project examining schools that had significant improvements in student achievement. The scale itself was used in Zandralyn Gordon's dissertation which provides some validity evidence. Zandralyn's dissertation has been included for your review.

Please let me know if you have any questions.

Good luck with your dissertation research.

Larry Jacobson, Ph.D.

Bureau of Educator Standards and Certification

Connecticut State Department of Education

Off. Ph. $\underline{860-713-6819}$

Fax: $\underline{860-713-7028}$ 


\section{Appendix G}

Means by Demographic subgroup and DLRS Dimensions

\begin{tabular}{|c|c|c|c|c|c|}
\hline Demographic & $\mathrm{N}$ & $\begin{array}{c}\text { Mission, } \\
\text { Vision, and } \\
\text { Goals Mean }\end{array}$ & $\begin{array}{c}\text { School } \\
\text { Culture Mean }\end{array}$ & $\begin{array}{c}\text { Leadership } \\
\text { Practices } \\
\text { Mean }\end{array}$ & $\begin{array}{c}\text { Shared } \\
\text { Responsibility } \\
\text { Mean } \\
\end{array}$ \\
\hline \multicolumn{6}{|l|}{ Gender } \\
\hline Female & 124 & 3.37 & 3.63 & 3.06 & 3.48 \\
\hline Male & 74 & 3.32 & 3.49 & 3.03 & 3.36 \\
\hline Total & 198 & 3.35 & 3.58 & 3.05 & 3.44 \\
\hline \multicolumn{6}{|c|}{$\begin{array}{l}\text { Years of Experience in } \\
\text { School }\end{array}$} \\
\hline 3 or less & 55 & 3.23 & 3.51 & 2.95 & 3.31 \\
\hline 4 to 6 & 46 & 3.36 & 3.56 & 3.13 & 3.53 \\
\hline $7+$ & 97 & 3.41 & 3.62 & 3.07 & 3.46 \\
\hline Total & 198 & 3.35 & 3.58 & 3.05 & 3.44 \\
\hline \multicolumn{6}{|l|}{ Programmatic level } \\
\hline Early Learning & 119 & 3.34 & 3.60 & 3.04 & 3.49 \\
\hline Middle & 35 & 3.38 & 3.56 & 3.06 & 3.42 \\
\hline Adolescent & 44 & 3.37 & 3.52 & 3.04 & 3.31 \\
\hline Total & 198 & 3.35 & 3.58 & 3.05 & 3.44 \\
\hline
\end{tabular}

